OPEN ACCESS

Edited by:

Vuk Uskokovic,

University of California, Irvine

United States

Reviewed by:

Victoria M. Wu,

Independent Researcher, Irvine,

United States

Jason Thomas Duskey,

University of Modena and Reggio

Emilia, Italy

${ }^{*}$ Correspondence: Pablo E. Vivas-Mejia

pablo.vivas@upr.edu

Specialty section: This article was submitted to

Nano-Based Drug Delivery,

a section of the journa

Frontiers in Medical Technology

Received: 10 March 2021

Accepted: 16 July 2021

Published: 10 August 2021

Citation:

Sharma RK, Calderon C and

Vivas-Mejia PE (2021) Targeting

Non-coding RNA for Glioblastoma

Therapy: The Challenge of Overcomes the Blood-Brain Barrier.

Front. Med. Technol. 3:678593.

doi: 10.3389/fmedt.2021.678593

\section{Targeting Non-coding RNA for Glioblastoma Therapy: The Challenge of Overcomes the Blood-Brain Barrier}

\author{
Rohit K. Sharma ${ }^{1}$, Carlos Calderon ${ }^{1}$ and Pablo E. Vivas-Mejia ${ }^{1,2 *}$ \\ ${ }^{1}$ Comprehensive Cancer Center, University of Puerto Rico, San Juan, PR, United States, ${ }^{2}$ Department of Biochemistry, \\ University of Puerto Rico, Medical Sciences Campus, San Juan, PR, United States
}

Glioblastoma (GBM) is the most malignant form of all primary brain tumors, and it is responsible for around 200,000 deaths each year worldwide. The standard therapy for GBM treatment includes surgical resection followed by temozolomide-based chemotherapy and/or radiotherapy. With this treatment, the median survival rate of GBM patients is only 15 months after its initial diagnosis. Therefore, novel and better treatment modalities for GBM treatment are urgently needed. Mounting evidence indicates that non-coding RNAs (ncRNAs) have critical roles as regulators of gene expression. Long non-coding RNAs (IncRNAs) and microRNAs (miRNAs) are among the most studied ncRNAs in health and disease. Dysregulation of ncRNAs is observed in virtually all tumor types, including GBMs. Several dysregulated miRNAs and IncRNAs have been identified in GBM cell lines and GBM tumor samples. Some of them have been proposed as diagnostic and prognostic markers, and as targets for GBM treatment. Most ncRNA-based therapies use oligonucleotide RNA molecules which are normally of short life in circulation. Nanoparticles (NPs) have been designed to increase the half-life of oligonucleotide RNAs. An additional challenge faced not only by RNA oligonucleotides but for therapies designed for brain-related conditions, is the presence of the blood-brain barrier (BBB). The BBB is the anatomical barrier that protects the brain from undesirable agents. Although some NPs have been derivatized at their surface to cross the BBB, optimal NPs to deliver oligonucleotide RNA into GBM cells in the brain are currently unavailable. In this review, we describe first the current treatments for GBM therapy. Next, we discuss the most relevant miRNAs and IncRNAs suggested as targets for GBM therapy. Then, we compare the current drug delivery systems (nanocarriers/NPs) for RNA oligonucleotide delivery, the challenges faced to send drugs through the BBB, and the strategies to overcome this barrier. Finally, we categorize the critical points where research should be the focus in order to design optimal NPs for drug delivery into the brain; and thus move the Oligonucleotide RNA-based therapies from the bench to the clinical setting.

Keywords: glioblastoma, blood-brain barrier, nanoparticles, non-coding RNAs, microRNA 


\section{INTRODUCTION}

GBM is the most common and aggressive malignant brain tumor in adults accounting for around $48 \%$ of all primary malignant brain tumors. The majority (90\%) of GBMs develop de novo (primary glioblastoma) and $10 \%$ progress from lower astrocytomas. Most GBM occurs spontaneously, although familial gliomas have also been noted (1). The lethality of GBMs is mostly due to the ability of cancerous cells to spread over the brain parenchyma and its high level of vascularization (2). Evidence has shown that the mean survival rate for diagnosed GBM is $8-15$ months and for recurring GBM the mean survival rate is $3-9$ months. The 5 -year survival rate is only $5 \%$ (3). The standard treatment for GBM patients includes surgery (to remove tumors, when possible) combined with radiotherapy (RT) and/or temozolomide (TMZ)-based chemotherapy (4). TMZ is a prodrug, which converts into its active metabolite via a non-enzymatic pathway (5). The active metabolite of TMZ targets guanine at the position of $\mathrm{O} 6$ and N7, preventing DNA replication and inducing apoptosis (6). Data from the European and Canadian trial (EORTC 26981/22981-NCIC) demonstrated that RT, followed by 6 monthly cycles of TMZ provides significant survival benefits with minimal additional toxicity in patients with GBM. They reported a median survival of 14.6 months with RT plus TMZ vs. 12.1 months with RT alone (6-8).

Other FDA approved treatment modalities for GBM treatment include bevacizumab (Avastin) an antibody against the Vascular Endothelial Growth Factor Receptor (VEGFR), carmustine (BCNU) also known as gliadel wafers $(4,8)$. The latter are composed of nitrosoureas which alkylate DNA by forming inter-strand crosslinks to prevent DNA from replication or transcription when implanted in the cavity of the resected tumor (9), lomustine, another alkylating agent of the nitrosourea type is highly lipid-soluble and able to crosses the BBB (10). Several therapeutic modalities for GBM in clinical trials include monoclonal antibodies targeting Epidermal Growth Factor Receptor (EGFR) (alone or conjugated with other drugs), chemotherapeutic agents (procarbazines, hydroxyureas, irinotecan, erlotinib, cyclophosphamide, and mTOR inhibitor), tumor treating fields (TTF) therapy, immunotherapies (vaccination, adoptive cell therapy, and immunostimulants), epigenetic therapy, oncolytic virus therapy, and gene therapy $(11,12)$. Despite all available diagnostic, prognostic, and therapeutic modalities, the GBM prognosis remains poor. It has been speculated that tumor heterogeneity and the presence of cancer stem cells in the tumors are major reasons for therapy resistance of GBM cells (13). Therefore, novel therapeutic approaches are needed to improve the survival and quality of life for GBM patients.

In the last two decades, ncRNAs have gained significance as potential targets against many cancer types, including GBMs (14). NcRNAs represent more than $60 \%$ of the human genome (15), and based on their length they are usually divided into two major types, small non-coding RNAs (sncRNAs), and long non-coding RNAs (lncRNAs). ncRNAs can also be divided into structural and regulatory functions. Structural ncRNA includes t-RNA, r-RNA, snRNAs, and snoRNAs, among others (16). Regulatory ncRNA includes mainly, the Xist (the ncRNA responsible for female $\mathrm{X}$ chromosome inactivation early during embryogenesis), the microRNAs (miRNAs), and lncRNAs. Although the role of miRNAs as posttranscriptional regulators of gene expression has been well-documented, the multiple potential roles of lncRNAs are presently under extensive investigation. In any case, dysregulation of miRNAs and ncRNAs in most cancer types including GBMs and therefore, these molecules have been considered as diagnostic, prognostic and therapeutic tools. MiRNA-based therapies are designed to target upregulated miRNAs with oligonucleotide miRNA inhibitors (OMIs) or against downregulated miRNAs with oligonucleotide miRNA mimics (OMMs) (17). LncRNAs and mRNA-coding genes are targeted with double-stranded RNAs (small interference RNA, siRNA). OMIs, OMMs and siRNA-based molecules are all referred to as interference RNA (RNAi) (17).

In the next sections, we discuss the current status of the RNAi-based therapies under investigation for GBM treatment, the proposed delivery methods for drug delivery into the brain, and finally, we address the research status of the strategies to overcomes the BBB for GBM treatment.

\section{DEREGULATION OF NON-CODING RNAS IN GBM}

After their discovery in Caenorhabditis elegans by Lee et al. (18) miRNAs were soon associated with the regulation of gene expression at the posttranscriptional (mRNA) level. Early expression profile studies showed deregulation of several miRNAs in many diseases including cancer $(19,20)$. Similarly, Brannan et al. in 1990 reported for the first time H19 as a lncRNA (21), and in 1991 Brown et al. reported the lncRNA Xist as responsible for the X-chromosome inactivation (22). All these efforts along with the sequencing of the human genome in 2001 made clear that close to 80\%) of the DNA encode ncRNAs. Further evidence confirmed that ncRNAs play a central role in the regulation of gene expression $(23,24)$. Remarkably, for Xist and other lncRNAs, such as in Air, only small segments in their sequences are highly conserved $(25,26)$. For instance, nearly $5 \%$ of mammalian lincRNAs (long intergenic non-coding RNAs that constitute more than half of lncRNAs transcripts in humans), which are typically restricted to short polynucleotide stretches, are conserved in zebrafish (27). Some mouse and human IncRNAs orthologs were able to phenotypically rescue zebrafish lincRNA loss of function indicating that at least some lincRNAs are functionally conserved across species (26).

Unlike lncRNAs, miRNAs are well-conserved across a diverse range of species (15). It is thought that due to the short size of the miRNA molecules, any change in their sequences will result in major effects on their functions (25). McCreight et al. analyzed the miRNA sequences of 13 primate species (Apes, Old World monkeys, New World monkeys, and Strepsirrhines) and observed that not only the seed region and the mature miRNA but also the pre-miRNA hairpin sequences are highly conserved across primates (28). 
Several studies have confirmed the relationship between ncRNAs expression and human diseases including cancer (29-31); neurological and neurodegenerative diseases such as Alzheimer's, Schizophrenia, Autism spectrum disorder, Parkinson's, Angelman syndrome, Huntington's disease among others (30). Deregulation of ncRNAs has also been associated with diseases related to endocrinology, reproduction, metabolism, immunology, neurobiology, muscle biology, and cancer (32).

\section{MicroRNAs}

MiRNAs are endogenous sncRNAs of around 22-24 nucleotides long which regulate gene expression at the posttranscriptional level by binding mainly to the $3^{\prime}$ untranslated ( $3^{\prime}$ UTR) regions of mRNAs (33). The genesis of miRNAs has been extensively described in the literature (34). Several expression profile studies using cell lines and tumor samples have identified many dysregulated miRNAs in GBM cell lines and GBM tumor samples compared with normal control samples $(35,36)$. Deregulation of those miRNAs could play important role in all steps of GBM initiation, progression, and tumor maintenance (37). Some of these miRNAs and their downstream molecular have been proposed as targets for GBM therapy $(36,38)$.

MiR-21, one of the first discovered miRNAs was shown to exhibit oncogenic properties (oncomiR) (39). MiR-21 regulates several tumor suppressor genes including PTEN, TIMP3, PDCD4, among others (39). Corsten et al. reported that suppression of miR-21 with locked nucleic acid (LNA)-antimiR21 oligonucleotides increased caspase activity and decreased cell viability of human GBM cells (A172 and U-87 MG). LNA against miR-21 also had beneficial effects on intracranially implanted GBM mouse models (40). Inhibition of miR-21 expression in T98G human GBM cells with catalytic nucleic acids (hammerhead ribozymes and DNAzymes) increased PTEN expression and decreased cell proliferation and invasion (41). Inhibition of miR-21 also increased apoptosis and sensitized chemo- or radiotherapy-resistant cells to other treatments (41). Piwecka et al. performed miRNA expression studies using miRNA microarrays, deep sequencing, and meta-analysis in GBM and peritumoral brain tissues obtained from the patients during surgery and compared their findings with normal brain tissues (42). Their findings identified 35 miRNAs which were either upregulated or downregulated in GBM $v s$. control samples. They proposed 30 of these miRNAs as novel biomarkers for GBM (42).

By using COX regression analysis, Srinivasan et al. identified 10 significant dysregulated miRNAs in GBM patients compared with normal brain samples (43). These miRNA signatures were able to discriminate between patients with high vs. low survival rates (43). Similarly, Jin and workers proposed a novel method for the prioritization of candidate cancer-related miRNAs which alter the expression of other miRNAs and coding genes across an entire biological network (44). To do this, they selected three important features: the average expression of a miRNA in multiple cancer samples, the average of the absolute correlation values between the expression of a miRNA and expression of coding genes, and the number of predicted miRNA target genes.
The clinical relevance of the top 20 miRNAs of this study was interrogated using microarray and/or RNA-Seq datasets available in "The Cancer Genome Atlas" (TCGA) data portal (http:// cancergenome.nih.gov) (44). MiR-22 emerged as the top relevant miRNA in GBM (44). An additional study reported that miR22 was downregulated in GBM tissue samples and GBM cell lines as compared with non-tumor tissues and normal human astrocytes, respectively (45). MiR-22 downregulation correlates with the upregulation of SIRT1 (NAD-dependent deacetylase sirtuin-1), a gene associated with the repression of p53-mediated apoptosis (46). Therefore, therapies increasing the miR-22 levels could have beneficial effects in GBM patients $(45,46)$.

In the most recent work, Boissinot et al. performed a high-throughput screen study in adult (U251) and pediatric GBM cells (KNS42) using a synthetic oligonucleotide library that mimics the annotated mature miRNAs (miRBase v16.0) and measured the reduction of cell proliferation in the cell lines following transfection of the mimics. This screening identified $\sim 100$ significantly cytotoxic miRNAs. Mir-1300 was shortlisted as the most potent and robust candidate miRNA. Further experiments revealed that ectopic expression of miR1300 decreased tumor growth in an orthotopic U-87 MG mouse model, indicating that miR-1300 is a potential candidate for therapeutic applications (47). Recently, miR-29a, a miRNA with tumor suppressor capabilities, was reported downregulated in GBM cells (U-251 MG, U-87 MG, U-373 MG, U-1242 MG, and T98G), glioma stem cells (GSCs) (GSC-11, GSC-20, GSC-28, GSC-267, GSC-295, and GSC-627), and human GBM tumors samples as compared with normal human astrocytes (NHAs) and normal brain tissues, respectively (48). When miR-29a was exogenously expressed in GBM (U-87MG) and GSCs (GSC267) cells, it induced apoptosis and inhibited cell growth, migration and invasion (48). In addition to miR-29a, miR370 was found to be downregulated in human glioma tissue samples, U-87 MG and U-251 MG cells as compared with control samples. Decreased levels of miR-370 have been associated with the malignant transformation of astrocytes into glioblastomas and astrocytomas (49). Transfection of OMIs or OMMs in U$87 \mathrm{MG}$ and U-251 MG cells showed that downregulation of miR370 is negatively associated with $\beta$-catenin (upregulation) and positively linked with nuclear FOXO3a (forkhead box protein) (49). $\beta$-catenin is a downstream molecule of the Wnt and Hedgehog signaling, the main pathway of GSCs renewal (50). Additionally, miR-320 was decreased while forkhead box protein M1 (FoxM1) was increased in radioresistant glioma tissues obtained from GBM patients (51). The direct binding of miR320 to FoxM1 was confirmed by bioinformatics and luciferase reporter assays (51). MiR-320 overexpression in U $251 \mathrm{MG}$ and U-87MG cells followed by infrared exposure, reduced cell survival, and increased apoptosis compared with controls (51). These findings also showed that miR-320 improves the radiosensitivity of glioma cells via down-regulation of Sirt1.

Collectively, numerous studies have demonstrated that several miRNAs are deregulated in GBM cell lines and GBM tumor samples. The selection of appropriate miRNAs as a target for GBM therapy (or any other disease) should identify the precise miRNA target genes as a single miRNA can regulate tumor 
suppressors and/or oncogenes at the same time (52). Similarly, a gene can be regulated by more than one miRNA (53). During the course of the disease, the expression of a particular miRNA may change, especially, in cancer stem cell populations, drugresistant cell populations, or in response to therapy (radiotherapy and/or chemotherapy). Also, the expression of a miRNA may be different (even opposite) in GBM cancer cells $v s$. the tumor microenvironment. Table 1 summarizes some relevant miRNAs that have been targeted with OMIs or OMMs in GBM mouse models.

\section{Long Non-coding RNAs}

LncRNAs are RNAs longer than 200 nucleotides that are not translated into proteins (32). Based on their genomic localization, orientation, and processing lncRNAs are divided into at least five categories: intergenic, intronic, bidirectional, and antisense lncRNAs (60). Classification of lncRNAs according to their function, is possible $(61,62)$. A study by Ma et al. revealed that the human genome expresses at least 270,044 lncRNAs (63). LncRNAs play important roles in the regulation of various biological processes in the nucleus, cytoplasm, and even in the extracellular space by mechanisms that include lncRNA-protein, lncRNA-RNA, lncRNA-miRNA, and lncRNA-DNA interactions (64). Moreover, evidence indicates that lncRNAs play a central role in other molecular events including regulation of mRNA stability, RNA splicing, chromatin structure, miRNA mediated gene regulation, protein, and enzyme function, and as extracellular signaling molecules (65). Similar to miRNAs, deregulation of lncRNAs includes, duplications/translocations/mutations in DNA sequences coding the lncRNAs, alteration in signaling molecules and transcription factors responsible for the lncRNAs regulation, modifications in the RNA recognition sites, and alterations in the levels of molecules interacting with a particular lncRNAs (66). However, the entire biological roles and molecular mechanisms of IncRNAs are still under investigation.

Deregulation of lncRNAs has been associated with all steps of carcinogenesis in most cancer types, including GBM (67). For example, the IncRNA LINC00152 is upregulated in GBM patients and was correlated with poor prognosis $(68,69)$. SiRNAmediated LINC00152 silencing suppressed tumor growth and invasion in both in vitro and in an intracranial GBM (U87MG cells) mouse model (68). Further experiments showed that LINC00152 regulates a miR-612/AKT2/NF-kB pathway to promote proneural-mesenchymal transition (PMT) (68). A recent study using available clinical and molecular GBM patient information and bioinformatics tools identified 10 lncRNAs that can be used as an independent prognostic factor for high-grade gliomas (70). Li et al. reported that an extremely poor overall survival of GBM patients was linked to the upregulation of the linc00645 lncRNA (71). ShRNA-mediated knockdown of linc00645 in U-251 MG and T98G GBM cells inhibited colony formation, invasion, and migration while the self-renewal ability (neurosphere formation) of these cells was reduced (71). In vivo studies where Linc00645 was knocked-out in U-251 MGLuc cells and intracranially injected nude mice reduced the tumor growth compared with a lncRNA control (71). Further molecular signaling pathway analysis showed that linc00645 targets the miR-205-3/Zinc Finger E-box-Binding Homeobox 1 (ZEB1) pathway (71). In other studies, Ren et al. demonstrated that siRNA knock-down of the IncRNA SNHG7 (small nucleolar RNA host gene 7, a lncRNA upregulated in several cancers, including GBM tissues and cell lines) in A172 and U-87 MG cells reduced cell proliferation, migration and invasion, and activated apoptosis. SiRNA-mediated SNHG7 knockdown also reduced tumor growth and metastasis in GBM xenograft (s.c.) mouse model (72). Ren et al. proposed that SNHG7 directly inhibits miR-5095 and activates the Wnt/Bcatenin signaling pathway. Additionally, inhibition of miR-5095 in A172 and U$87 \mathrm{MG}$ cells increased the expression of CTNNB1, the gene encoding $\beta$-catenin (72). More recently, Chen et al. reported that SNHG7 acts as a miRNA sponge by reducing miRNA-449b-5p levels, increasing MYCN (a miRNA-449b-5p target gene), and promoting GBM progression (73). In other studies, Han et al. reported that the Wnt/ $\beta$-catenin signaling pathway in GBM is inhibited by the IncRNA MIR22HG through the loss of miR22-3p and miR-22-5p (74). Furthermore, MIR22HG was highly abundant in GBM patient samples and its expression correlated with poor prognosis. This research team also identified SFRP2 and PCDH15 as direct targets of miR-22-3p and miR-22-5p in GBM cells. Additionally, they designed a small inhibitor (AC1L6JTK) inhibited tumor growth in s.c. GBM mouse model (74).

Another lncRNA that is increased in GBM tumor samples compared to normal brain tissues is the NF-kappa B interacting lncRNA (NKILA). High levels of NKILA correlated with reduced GBM patient survival (75). An shRNA containing lentiviral vector against NKILA showed that this lncRNA stimulates the activity of the hypoxia signaling pathway, the Warburg effect, and angiogenesis in GBM cells (75). These effects were reversed when 20(S)-Rg3 monomers (an anti-cancer agent and apoptotic inducer that interfere with multiple signaling pathways) (76) were injected s.c. in LN229 or U-87 MG tumor-bearing mice. Furthermore, 20 (S)-Rg3 inhibited the expression of NKILA and reversed the stimulation of the Warburg effect and angiogenesis in LN229 and T98G glioma cells (75).

Many reports have shown a direct correlation between lncRNA expression levels and TMZ resistance (77-80). For instance, Cai et al. showed that the IncRNA MALAT1 was significantly upregulated in TMZ-resistant U251 GBM cells. Lentiviral-based knockdown of MALAT1 decreased TMZ resistance in GBM cells as confirmed by the reduction of cell growth and increased apoptotic rates (77). A significant reduction in tumor volume and tumor weight was observed when U251/TMZ cells were injected s.c. in nude mice. Further experiments indicated MALAT1 suppressed the expression of miR-101, suggesting a potential mechanism for MALATI in TMZ resistance (77). In separate experiments, $\mathrm{Wu}$ et al. performed a lncRNA microarray of RNA extracted from patientderived LN229 cells and its TMZ resistant counterpart 229R GBM cells. The microarray identified lnc-TALC (temozolomideassociated lncRNA in glioblastoma recurrence) as one of the most abundant LncRNAs that was expressed differently between the two cell types. CRISPR-Cas9-mediated knockdown of lnc-TALC 
TABLE 1 | List of most relevant MiRNAs as potential targets against GBM.

\begin{tabular}{|c|c|c|c|c|}
\hline MicroRNA & $\begin{array}{l}\text { Up-or-down } \\
\text { regulated }\end{array}$ & Biological role & $\begin{array}{l}\text { GBM model and therapy delivery } \\
\text { method }\end{array}$ & References \\
\hline miR-10b & Upregulated & $\begin{array}{l}\text { OncomiR, promotes proliferation of } \\
\text { GBM and GSCs }\end{array}$ & $\begin{array}{l}\text { Human GSC (GBM8) and mouse } \\
\text { GL261 cells implanted InCr. Therapy: } \\
\text { anti-miR IT, IV, and with osmotic } \\
\text { pumps. }\end{array}$ & $(54)$ \\
\hline miR-486-5p & Upregulated & $\begin{array}{l}\text { OncomiR, enhances the survival of } \\
\text { GBM stem cells }\end{array}$ & $\begin{array}{l}\text { Neurosphere-derived xenografts } \\
\text { (GBM1A and Mayo39 cells) implanted } \\
\text { InCr. Therapy: nano formulation of } \\
\text { anti-miRs, InCr }\end{array}$ & $(55)$ \\
\hline $\operatorname{miR}-21-5 p$ & Upregulated & $\begin{array}{l}\text { OncomiR, promotes tumor cell } \\
\text { survival and invasiveness, involved in } \\
\text { TMZ resistance }\end{array}$ & $\begin{array}{l}\text { U-251 MG cells implanted SC } \\
\text { Therapy: antisense miR- } \\
\text { 21/oligofectamine, IT }\end{array}$ & $(56)$ \\
\hline miR-34a & Downregulated & Tumor Suppressor, modulates EGFR & $\begin{array}{l}\text { U-87 MG cells implanted SC and InCr. } \\
\text { Therapy: miR-34 as } \\
\text { polyglycerol-based polyplex } \\
\text { formulation, IT and IV }\end{array}$ & $(57)$ \\
\hline miR-128-3p & Downregulated & $\begin{array}{l}\text { Tumor suppressor, inhibits metastasis } \\
\text { and epithelial-mesenchymal transition }\end{array}$ & $\begin{array}{l}\text { U-251GM cells implanted SC } \\
\text { Therapy: LV-miR +/- TMZ: IP }\end{array}$ & (58) \\
\hline miR-143-3p & Upregulated & OncomiR, increase cell proliferation & $\begin{array}{l}\text { U-87 GM cells implanted SC. } \\
\text { Therapy: liposomal anti-miR, IP }\end{array}$ & (59) \\
\hline miR-148a/miR-296-5p & Controversial & OncomiR or Tumor suppressor & $\begin{array}{l}\text { Human GBM derived neurospheres } \\
\text { (GBM1A) implanted InCr. Therapy: } \\
\text { PBAE nano-miRs mimics NPs, InCr }\end{array}$ & $(55)$ \\
\hline
\end{tabular}

InCr, intracranial; IT, intratumoral; IP, intraperitoneal; IV, intravenously; NPs, nanoparticles.

significantly decreased cell viability, promoted cell apoptosis, and inhibited colony formation and proliferation following TMZ treatment of TMZ- resistant GBM cells. By contrast, overexpression of lnc-TALC in LN229 and HG7 GBM cells reduced apoptosis and increased cell proliferation and colony formation after TMZ treatment. Tomography studies in mice implanted intracranially with LN229 and 229R cells revealed that TMZ resistant tumors did not respond to TMZ treatment while knockdown of lnc-TALC restored the sensitivity to the drug (78). Further evidence showed that lnc-TALC binds to miR-20b-3p with the concomitant expression of c-Met (78).

Similarly, it has been found that levels of the lncRNA SOX2OT are higher in TMZ resistant cells and recurrent GBM patient samples compared with normal human astrocytes (NHA). Knockdown of SOX2OT suppressed cell proliferation, promoted apoptosis, and enhanced TMZ sensitivity (79). Further studies showed that TMZ resistance was achieved by the interaction of SOX2OT with ALKBH5, a mammalian dioxygenase that oxidatively demethylates $\mathrm{m}$ (6) A in the mRNA (79). Recent studies confirmed that knockout of ALKBH5 enhanced the efficiency of immunotherapy and prolonged survival of mouse pre-implanted with B16 mouse melanoma or CT26 colorectal carcinoma cells (81). Mazor et al., using mathematical models to analyze multiple molecular pathways at the same time (82), RNA sequencing, and gene expression profiling datasets identified TP73-AS1 lncRNA as overexpressed in primary GBM samples and GSCs compared with normal brain tissues. To clarify the role of this lncRNA, the authors of this study performed a viral infection of a CRISPR interference (CRISPRi) targeting TP73-AS1. Results indicated that TP73-AS1 enhances TMZ resistance by promoting the expression of ALDH1A1 (aldehyde dehydrogenase 1 family member A1) (82). ALDH1A1 is a well-known marker of cancer stem cells and a drug resistance promoter in cancer cells (82).

Together, several dysregulated lncRNAs have been identified in GBM cell lines and GBM tumor samples, including TMZ resistant cells. More studies are needed to clarify the role of lncRNA in GBM initiation, progression, and drug resistance. Additional, therapeutic experiments using orthotopic and patient-derived GBM cells are required to confirm the beneficial effects of targeting specific lncRNAs in GBM tumors. Table 2 summarizes lncRNA that have been targeted with siRNAs or small molecule inhibitors in GBM mouse models.

\section{DELIVERY STRATEGIES FOR RNAi-BASED THERAPIES AGAINST GBM}

Several factors limit the use of RNAi-based therapy for cancer treatment. RNAi-based molecules are rapidly degraded in the circulation and cleared by the renal system. They activate immune responses, and due to their negative charge, they are not able to cross the cell membrane (84). Part of these obstacles has been solved using NPs which extend the half-life of RNAi molecules in the circulation. However, once inside cells, NPs-RNAi are entrapped in the endolysosomal pathway and degraded (84).

Many NPs have been proposed for the systemic delivery of RNAi-based molecules, including liposomes, polymeric NPs, micelles, dendrimers, artificial DNA nanostructures, silica NPs, 
TABLE 2 | List of relevant deregulated IncRNAs proposed as therapeutic targets against GBM (GBM mouse models used in the study).

\begin{tabular}{|c|c|c|c|c|}
\hline LncRNA & $\begin{array}{l}\text { Up-or-down } \\
\text { regulated }\end{array}$ & Biological role & Mouse model used for therapy & References \\
\hline SNHG7 & Upregulated & $\begin{array}{l}\text { Inhibition of miR- } 5095 \text { and activation } \\
\text { of Wnt/ } \beta \text {-catenin signaling pathway. }\end{array}$ & xenograft experiments in nude mice & $(72)$ \\
\hline MALT1 & Upregulated & EGFR-induced NF- $\kappa$ B activation & $\begin{array}{l}\text { U-87 MG cells implanted InCr } \\
\text { Therapy: Ml-2 small molecule } \\
\text { inhibitor, IP }\end{array}$ & (83) \\
\hline IncRNA- TALC & $\begin{array}{l}\text { Upregulated in } \\
\text { TMZ resistant cells }\end{array}$ & $\begin{array}{l}\text { Promotes O6-methylguanine- DNA } \\
\text { methyltransferase expression, TMZ } \\
\text { resistance }\end{array}$ & $\begin{array}{l}\text { GBM cells (LN229/229R and 229R } \\
\text { Scra/229R KD_Inc) implanted InCr. } \\
\text { Therapy: TMZ, IP }\end{array}$ & (78) \\
\hline SOX2OT & $\begin{array}{l}\text { Upregulated in } \\
\text { TMZ resistant cells }\end{array}$ & $\begin{array}{l}\text { IncreasesSOX } 2 \text { expression and } \\
\text { activate the } \mathrm{Wnt} 5 \mathrm{a} / \beta \text {-catenin } \\
\text { signaling pathway, TMZ resistance }\end{array}$ & $\begin{array}{l}\text { U87TR-sh-NC and } \\
\text { U87TR-sh-SOX2OT cells implanted } \\
\text { SC. Therapy: TMZ, IP }\end{array}$ & (79) \\
\hline MIR22HG & Upregulated & $\begin{array}{l}\text { Inducer of the Wnt/ } \beta \text {-catenin signaling } \\
\text { pathway }\end{array}$ & $\begin{array}{l}\text { U-87MG cells implanted SC. } \\
\text { Therapy: AC1L6JTK small-molecule } \\
\text { inhibitor, IP }\end{array}$ & $(74)$ \\
\hline
\end{tabular}

InCr, intracranial; IT, intratumoral; IP, intraperitoneal; IV, intravenously; NPs, nanoparticles.

nanotubes, metal NPs (mostly, Fe-, Au, and Se-based), and quantum dots, among many others (85-90). Although all of these NPs have been proposed as drug carriers for cancer treatment, few have been tested in relevant animal models of cancer. NPs are modified with ligands to increase their stability in serum (i.e., using polyethylene glycols, PEG) and/or to improve the endosomal escape (i.e., with polyethylenimine, PEI) (passive targeting). Depending on the construction material, NPs are derivatized with peptides, antibodies, carbohydrates, or other cell or tissue-specific markers (active targeting) (84, 91, 92). Important parameters to take into account with NPs for cancer treatment are their size, charge, and biodegradability (in particular, metal NPs accumulate in the organs and are therefore toxic) $(90,93-97)$. It is speculated that $50-200 \mathrm{~nm}$ in diameter are an ideal NP size for effective retention on the tumor tissues, and 20-50 nm for drug delivery through the BBB $(90,98)$ (see section Viral-Based Delivery for the discussion of RNAi delivery through the $\mathrm{BBB}$ ). In terms of the charge, positively charged NPs enter easily inside cells and therefore are more toxic compared with negatively charged or neutral NPs $(97,99)$. However, positively charged NPs are more rapidly phagocytized by the mononuclear phagocyte system which negatively impacts their accumulation in the tumors (100). Also, the NP surface is cover with different proteins which could change their size and their surface characteristics as they travel in the circulation and organs (101). These modifications (protein corona) are not well-investigated.

PEI-coated $\mathrm{Fe}_{3} \mathrm{O}_{4}$ NPs with siRNA were used for the silencing of the repressor element 1-silencing transcription factor (REST) gene in U-87 MG and U-251 GBM cells. The inhibition of REST significantly decreased cell viability and migration in these cells (90). Qui et al. effectively silenced Bcl-2 and VEGF in U-87 MG cells when siRNAs were delivered as a complex with $\beta$-cyclodextrin $(\beta$-CD)-modified dendrimer-entrapped gold nanoparticles (Au DENPs) (102). More recently, Li et al. proposed a composite NP of cationic liposomes loaded with YAP (yes-associated protein 1)-targeting siRNA and doxorubicin and coated on the exterior with gold nanorods. These NPs silenced YAP in GBM cells and reduced tumor growth when systemically injected in orthotopic GBM mouse models (103). Currently, most of these metal NPs as well as liposomes, polymeric NPs, and other composites are used in combination (i.e., gold NPs and liposomes) and/or modified with ligands to improve their stability and specificity (see below).

\section{Liposomes and Polymeric NPs}

Liposomes are artificial phospholipid vesicles that form a "coreshell" structure and can be readily loaded with therapeutic agents (104). Lipids commonly used for liposome preparation are biocompatible, biodegradable, and of low toxicity. Liposomes increase the distribution of delivered agents, reduce toxicity, and extend half-life. Liposomes can be customized based on the feasibility of the target cell or tissue by modifying their surfaces with a variety of functional moieties $(17,105,106)$. For in vivo applications, PEGylation (mostly with PEG-2000) on the liposome surface is commonly used (107). PEGylated liposomes acquire hydrophilicity on the surface, which might minimize the non-specific interaction with serum components by involving steric shielding and thereby increasing circulation time and overall stability of the NP (108). Some disadvantages of using PEGylated liposomes include the activation of immune responses and allergies (109). Furthermore, the PEG moiety hinders the interaction of liposomes with the target cell surface which could either decrease their cellular uptake, reduce their endosomal escape, and promote the degradation of the cargo in lysosomes (110). It is speculated that liposomes are accumulated in tumor tissues by passive targeting by virtue of an apparent tumor property known as "Enhanced Permeability and Retention" (EPR) effect $v s$. other tissues of the body, (110). The molecular and biological basis of the EPR are not well-understood (111).

Numerous studies have reported effective delivery of liposomes to glioblastoma cells. Ravi et al. used a liposomal formulation loaded with ferritin heavy chain 1 (FTH1)-targeted siRNAs to treat patient-derived xenograft glioblastoma initiating 
cells (GIC) (112). Kato et al. delivered (intratumorally) MGMTtargeted siRNAs loaded LipoTrust EX Oligo cationic liposomes in s.c. implanted Glioma-initiating cells (GIC)-derived tumors, and by osmotic pumps (s.c. implanted) in intracranially implanted GIC tumors (113). Their results showed that GIC tumors were sensitized to TMZ treatment (113). Our research team showed that a liposomal formulation of OMIs against miR-143 reduced tumor growth in a xenograft (s.c.) GBM mouse model (59). Despite their extensive use and their excellent biocompatibility, liposomes possess some disadvantages such as drug leakage and poor stability on storage leading to a short shelf-life (88). Although some siRNA-liposome formulations have advanced to clinical trials, and one to the clinic, none of them have been intended for brain tumors.

Polymeric NPs are solid-like colloidal particles synthesized with biodegradable polymers such as chitosan, collagen, or nonbiodegradable polymers such as poly (lactic acid) (PLA) and poly (lactic-co-glycolic acid) (PLGA) having a size range of $50-300 \mathrm{~nm}$. It is speculated that compared with liposomes, polymeric NPs accumulate in cells of the target site due to their small size and penetration through capillaries. However, their synthesis is more complex than liposomes $(88,105)$ and additional optimization procedures are required. Danhier et al. used convention enhanced delivery (CED) (see section ViralBased Delivery) to deliver EGFR- and galectin-targeted siRNAs as chitosan lipid nanocapsides to orthotopic (U-87 MG cells) GBM mouse models (114). They observed that the survival was increased significantly in mice treated with this formulation when compared with mice injected with each siRNA-chitosan formulation independently (114). Van Woensel et al. delivered a Galectin (Gal-1)-targeted siRNA-chitosan NPs intranasally to GBM mouse models (intracranially implanted GL261-WT or GL261-BFP tumor cells). Gal-1 which is overexpressed in GBM, was reduced by more than $50 \%$ as a result of this treatment (115). Intranasal delivery of the Gal-1-targeted siRNA-chitosan formulation in murine GBM models altered the tumor microenvironment, incremented CD4+ and CD8+ $\mathrm{T}$ cell numbers, sensitized cells to chemo and immunotherapy, and prolonged the animal survival (116). In other experiments, Ye et al. developed an angiopep-2-modified cationic PLGA nanoparticle to deliver Gefitinib (a tyrosine kinase inhibitor) and showed that this formulation effectively crossed the BBB and reduced the tumor growth in GBM mouse models (117).

Hybrids of lipids and polymeric particles have also been developed to deliver small molecules and siRNAs $(118,119)$. Dahlman et al. prepared a lipopolymer NP (LPNP) by conjugating epoxide-terminated lipids to low-molecular-weight polyamines (119). Yu et al. used this LPNP formulation to transfect siRNAs in brain tumor-initiating (BTIC) GBM cells (94). BTIC are present in brain tumors and possess stem cell properties including self-renewal and differentiation capacity into neural lineages (120). Moreover, BTIC are involved in tumor initiation, recurrence, and therapy resistance (94). BTIC are small in numbers relative to GBM cells, but their eradication is challenging as they survive chemotherapy and radiotherapy; they also reside in sites/conditions where therapies are less effective. Additionally, BTIC are heterogeneous in nature, stimulate epigenetic abnormalities, and rapidly migrate to normal cell sites to generate new GBM cell populations. However, targeting BTIC compared with other GBM cells could be a more effective approach for non-recurrent GBM treatment $(87,94)$. Yu et al. used LPNPs loaded with siRNAs against four transcription factors (SOX2, OLIG2, SALL2, and POU3F2); all responsible for proneural BTIC acquisition (94). Compared with non-targeted siRNA control NPs, intratumoral injection of siRNAs containing LPNPs increased the median survival of patient-derived BTIC xenograft in GBM mouse models (94). Likewise, GuerreroCázares et al. developed biodegradable poly ( $\beta$-amino esters) (PBAEs) to deliver DNA in to BTIC (87). PBAEs are considered advanced cationic NPs which have been successfully used for gene delivery (121). The ester bonds of PBAE are readily cleaved by hydrolysis with effective release of the payload with minimum cytotoxicity (89). Green et al. used PBAE NPs to deliver miRNA mimics of miR-148a and miR-296-5p in orthotopic human GBM xenograft mouse models (89). Intratumoral administration of these NPs inhibited tumor growth and prolonged the survival of the animals $(89,122,123)$. More recently, the same research group showed that the delivery of various siRNAs (against Robol, YAP1, NKCC1, EGFR, and survivin) within the same PBAE nanoparticle caused GBM cell death and reduced GBM cell migration (96). Intratumoral administration of this formulation reduced tumor burden in a xenograft (SC) GBM mouse model (96). More studies in relevant orthotopic GBM mouse models are needed to confirm that systemic administration of all of these NPs are able to cross the BBB and deposit their cargo in the tumor cells.

\section{Bacterial Toxins}

Bacterial toxins (specifically AB-type toxins), such as anthrax toxin (AT) and diphtheria toxin (DT) or Pseudomonas exotoxin have been tested as promising tools for RNAi delivery (124). As these toxins have natural mechanisms to penetrate the cells, they can be further modified for drug delivery purposes (124-126). Besides, their distinctive structure allows their natural transport via receptor-mediated endocytosis and crossing the endosomal membranes via a transmembrane pore (124). When detoxified DT chimeras were used as protein-delivery vectors, high translocating efficiencies of cargo proteins of variable sizes $(>100$ $\mathrm{kDa}$ ), structural motifs, and diverse stabilities were obtained (125). Dyer et al. successfully delivered Syntaxin5 (Synt5)targeted siRNA in various primate cell lines (HeLa, THP-1 and Vero) using deactivated AT. Following transfection, a significant downregulation of Synt5 expression was observed compared with siRNA transfection with the nucleofection methods (126). Arnold et al. explored whether attenuated diphtheria toxin (aDT) could be used as a delivery vehicle for siRNAs against integrin- $\beta 1$ (ITGB1)- and eukaryotic translation initiation factor 3 subunit b (eIF-3b)-targeted siRNAs in patient-derived GBM cells. First, they conjugated DT with cysteine (Cys); next, the Cys was modified with a maleimide cross-linked to dibenzocyclooctyne (DBCO) group and the siRNA molecules were attached to the DBCO. When the conjugated DT was added to GSCs, significant reductions in the mRNA levels of ITGB1 and eIF$3 \mathrm{~b}$ were observed (127). More studies using bacterial toxins for 
RNAi delivery should be performed in GBM cells and GBM mouse models.

\section{Stem Cell-Derived Exosomes}

Besides their use in prognosis, exosomes have gained potential use as drug delivery vehicles $(128,129)$. Compared with other NPs, exosomes exhibit less immunogenicity when derived from autologous cells and therefore they are less toxic compared with other artificial delivery vehicles (130). Due to the phospholipid bimolecular layer, exosomes can cross the plasma membranes (131). Their small size can facilitate their extravasation and diffusion in tumor tissues which can facilitate their transport across the BBB. Katakowski et al. used mesenchymal stromal cell (MSCs)-derived exosomes as carriers for miRNA delivery. They transfected MSCs with miR-146b-expressed plasmid and the isolated exosomes were injected intracranially in a xenograft rat model. The miR146b-exosomes reduced the tumor volume 5 days after the treatment (132). In another study, secreted exosomes were obtained from patient-derived GSCs engineered to express the miR-302-367 (133). Exosomes were delivered into naïve neighboring GSCs and resulted in repression of target genes, CXCR4/SDF1, SHH, cyclin D, cyclin A, and E2F1. The orthotopic xenograft of both naïve and ectopically expressing miR-302-367 GSCs altered the tumor development in mouse brain (133). The microRNA cluster miR-302-367 has previously been considered as a potential treatment for glioblastoma (134).

In a similar study, Lee et al. utilized MSCs to deliver miR124 mimics in glioma xenograft mouse models. They transfected the MSCs with Cy3-labeled miR-124 mimics and administered them intracranially in the U-87-MG derived xenograft GBM mouse model (135). The results indicated that MSCs were able to deliver the synthetic exogenous miRNA mimics to glioma cells and glioma stem cells. However, the therapeutic potential of the formulation was not evaluated (135). Wang et al. studied the inhibitory effect of human bone marrowderived mesenchymal stem cell (hBMSC)-derived exosomes in GBM tumor progression. They observed that hBMSC-derived exosomes overexpressing miR-34a suppressed MYCN expression and decreased cell proliferation, invasion, and migration; it reduced tumor growth in xenograft mouse models (136). Yu et al. have observed the inhibition of glioma progression by downregulation of AGAP2 (ArfGAP with GTPase domain, ankyrin repeat and $\mathrm{PH}$ domain 2) when exosomes were released from miR-199a-overexpressing MSCs in vitro and in vivo experiments (137). Despite the enormous potential of exosomes as RNAi carriers, additional in vivo experiments using orthotopic GBM mouse models should be performed.

\section{Viral-Based Delivery}

Viral vectors including retrovirus, adeno-associated virus (AAV), and herpes simplex virus (HSV) have been studied for several years as a tool for gene therapy and as drug delivery vehicles (138-140). Lentiviral vectors have also emerged as efficient delivery vehicles for stable gene expression of shRNA in GBM cells (141). Yang et al. used lentivirus-based siRNA delivery to target small supernumerary marker chromosomes 1A (SMC1A). This gene plays an important role in genome stability including
DNA replication, repair, and engaging proteins of cell-cycle networks (142). After infection of GBM cells with lentivirus containing SMC1A-targeted siRNAs, a 50 and $100 \%$ reduction in cell proliferation were obtained at 5 and 14 days, respectively (142). Matsuda et al. performed a remarkable study by developing a Hemagglutinating virus of Japan envelope (HVJ-E) which was obtained with inactivated Sendai virus. HVJ-E could be used as a delivery vector of siRNA, DNA, proteins, and other anti-cancer drugs (143). In this study, siRNA was incorporated in the HVJE vector to knockdown mitotic motor protein Eg5, which has important functions in the early stages of mitosis, centrosome separation, and formation of the bipolar mitotic spindle (143). Therefore, knockdown of Eg5 is beneficial as it is able to arrest the cell in the mitotic stage and leading to apoptosis. One of the most significant outcomes of this study was the complete eradication of all the intradermal U-118MG tumors and approximately $80 \%$ of intracranial implanted U-118 MG tumors (143).

In another study, epidermal growth factor receptor (EGFR) gene silencing was performed in human gli36-Luc glioma cells. HSV-1-based amplicons expressing EGFR specific siRNAs against two different locations pHSVsiEGFR I and pHSVsiEGFR II, respectively, were constructed. The knockouts at both loci resulted in a significant growth reduction of glioma cells in vitro and in vivo studies (144). HSV-1 vector was also employed in post-transcriptional inhibition studies of Rad51 protein in gli36-luc glioma cells containing target-specific siRNA combined with radiation therapy. Rad51 performs an important function in homologous strand exchange, which is a key step in DNA repair through homologous recombination (HR). Results of this study confirmed that the silencing of Rad51 improves the radiation-induced death of tumor cells (145). In another study, a recombinant adeno-associated virus (rAAV) expressing short hairpin RNA (shRNA) was produced in the vertebrate Spodoptera frugiperda (Sf9) cell line. This vector reduces the expression of Hecl protein (highly expressed in cancer 1) which is responsible for the beginning of the anaphase by regulating chromosomal segregation, microtubule interactions, and spindle checkpoint signaling. When the vector ( $\mathrm{rAAV}$-shHec1) was injected intratumorally it selectively killed mitotically active glioma tumor cell (U251) in the xenografts tumor model (146). Lee et al. developed three-way-junction (3WJ)-based RNA NPs (RNP) derived from a well-established bacteriophage phi29 packaging RNA (pRNA) system. These bacteriophage-derived NPs were resistant to clinically relevant doses of I-125 and Cs-131 radiation (147). Further studies with multi-valent folate (FA)conjugated 3WJ RNP loaded with LNA against miR-21 reduced the expression of this miRNA and incremented the expression of its target genes (PCDD4 and PTEN) in GBM cells in vitro and in vivo (148).

Despite the significant advancement with the use of viral vectors as cytotoxic agents and/or for gene therapy, clinical trials have failed (149-151). None of the proposed viral vectors against GBM have been approved clinically $(152,153)$. Nevertheless, a new category of AAV vector associated with exosomes, which are termed as vexosomes, has been reported $(150,154)$ and their applications were studied recently $(149,150,154)$. These vectors were efficiently transduced and were more resistant in 


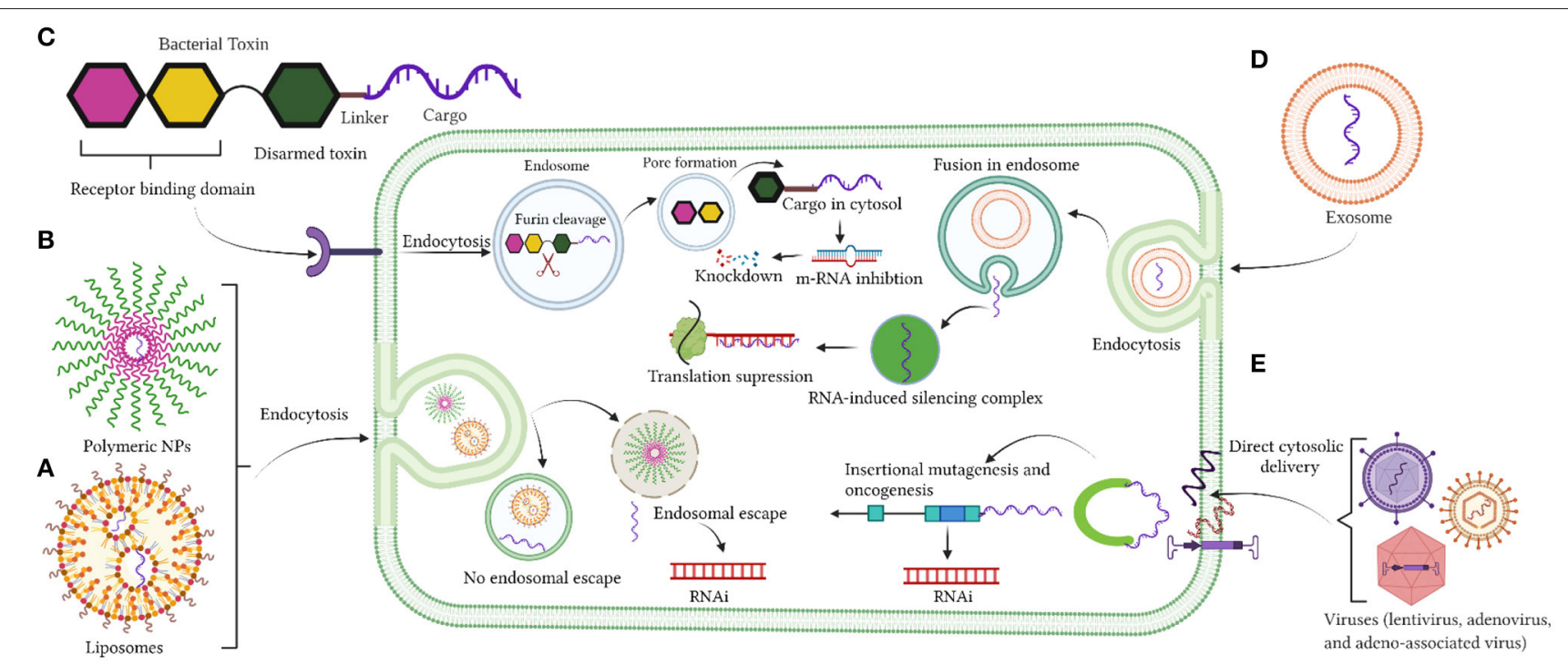

FIGURE 1 | (A-E) Delivery strategies by liposomes nanoparticles, polymeric nanoparticles, bacterial toxin, exosomes, and viruses. Created with BioRender (https:// Biorender.com/).

neutralizing anti-AAV antibodies compared to conventionally purified AAV (149). Although these vectors have not been investigated as delivery carriers for GBM treatment, they were very efficient in delivering DNA to the central nervous system (CNS) in mouse studies (150). Vexosomes were also used to deliver inducible caspase 9 (iCasp9) in Huh7 hepatic cancer cells and in hepatocellular carcinoma (HCC) xenograft mouse models (154). More exploratory studies are needed with the use of Vexosomes as drug delivery vehicles. Figures 1A-E summarizes the current delivery strategies under investigation for drug delivery into the brain.

\section{THE BLOOD-BRAIN BARRIER IS THE CRITICAL FACTOR FOR THE SUCCESSFUL DESIGN OF USEFUL DRUGS FOR GBM TREATMENT}

The Blood-Brain Barrier (BBB) is the physical/anatomical barrier that protects and regulates the homeostasis of the Central Nervous System (CNS) (Figure 2). It is located between the blood microcirculation system and the brain parenchyma. The BBB is composed mainly of a non-fenestrated layer of brain microvascular endothelial cells, which are tightly bound together by Tight Junctions (TJ), surrounded by a specialized basal lamina that is shared with pericytes and astrocytic endfeet, and interconnected by neural endings and microglia $(155,156)$. TJ's, known also as Zona Occludens, contain major integral membrane proteins such as claudins and occudins. These proteins interact with peripheral membrane proteins known as Zonula Occludins $(\mathrm{ZO})$ in order to maintain the integrity of the BBB. This integrity allows the BBB to be highly selective and regulate the entry of nutrients, ions, and other molecules. It also protects the CNS against neurotoxic substances. Likewise, pericytes are key regulators of vascular function throughout the body as they communicate with astrocytes and support BBB maintenance in the postnatal brain. Pericytes also regulate the expression of transporters such as the lysophosphatidylcholine (LPC) transport catalyzed by the $\mathrm{Na}^{+}$-coupled LPC symporter 1 (NLS1) which is responsible for the transport of docosahexaenoic acid (DHA, an omega-3 fatty acid) across the BBB (157). Pericytes enfold the CNS endothelium which forms a basal lamina that attracts astrocytic endfeet during development (158, 159). Astrocytes, the most abundant cell type in the brain, are important metabolic sensors and make a significant contribution to BBB development and function (160). Astrocytes regulate signaling pathways that maintain junctional complexes and produce an additional barrier called the glia limitans $(161,162)$. Together, astrocytes and pericytes play an important role in the integrity of the BBB (163).

Generally, the BBB precludes brain entry of $100 \%$ of large molecules and $98 \%$ of small molecules $(164,165)$. Although the $\mathrm{BBB}$ is compromised in GBM patients, this barrier is considered the rate-limiting factor for the development of all new therapeutics for the treatment of GBM; and other neurological disorders (163). Thus, research efforts are focused on finding ways to breach, bypass, and target the BBB to successfully develop optimal treatments against CNS-related conditions. Breaching the BBB consists of disrupting the neurovascular junction by chemical or mechanical insults, allowing treatments to enter the brain parenchyma. One example of this is the focused ultrasound-induced BBB opening (FUS-BBB) (166). Here, microbubbles are administered into the circulation and a non-invasive FUS is performed in the brain region of interest. When submitted to the low-energy toned ultrasound, the microbubbles burst and transiently permeate the BBB, causing a physical cavitation effect. This technique is being evaluated for the treatment of Alzheimer's disease (AD), amyotrophic 


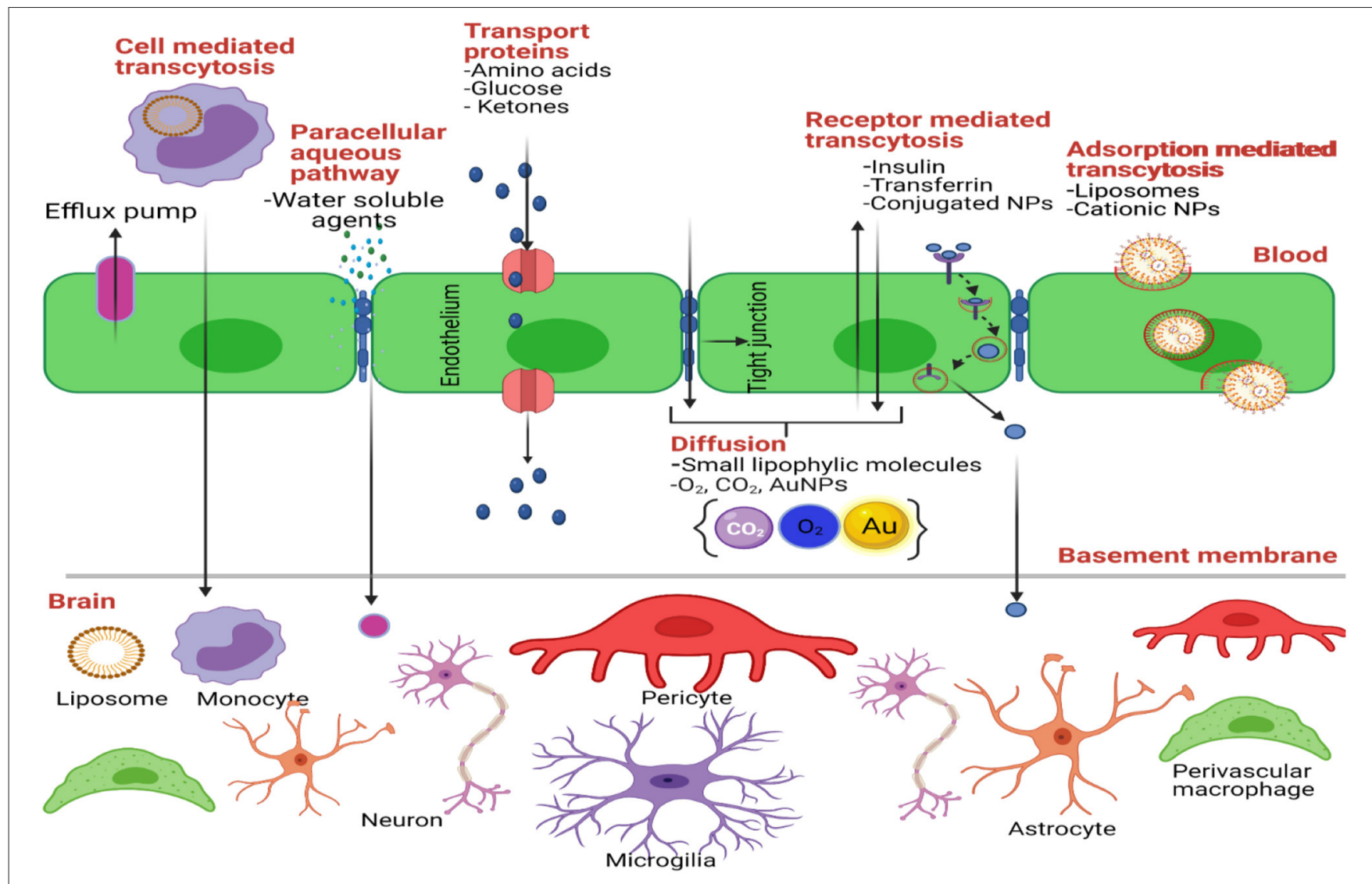

FIGURE 2 | Transport mechanisms through the BBB. Created with BioRender (https://Biorender.com/).

lateral sclerosis (ALS), Parkinson's disease, and GBM (166). Due to successful preclinical studies in GBM, FUS-BBB is being evaluated under Phase I clinical trials for chemotherapy with doxorubicin and carboplatin (167).

Bypassing the $\mathrm{BBB}$ consists on finding new ways to deliver CNS treatments to the brain without dealing with the BBB. One way of achieving this is trading the oral, the intravenous (i.v.) or the intraperitoneal (IP) administration with non-conventional routes such as convection-enhanced delivery (CED), delivery to the cerebrospinal fluid (CSF) via intrathecal (IT) or intraventricular (IVN) routes, and intranasal delivery (168). Direct intratumoral drug administration and subcutaneous (s.c.) implantation of osmotic pumps have also been used for drug delivery using GBM mouse models $(54,55)$. In CED a pressure gradient is generated in a tip of an infusion catheter implanted in the interstitial spaces of the CNS. CED was used to deliver chitosan-siRNA NPs in GBM mouse models (114). Kim et al. implanted U-87MG cells in the brain of mice and compared the tumor distribution of OMI (targeting Let-7) administered intratumorally (IT), intrathecally (ITc) and intraventricularly (Ivn). IT administration led to a high rate of OMI accumulation in the brain tumor cells (169). However, Ivn administration showed a greater distribution of the OMI in the brain tissues (169). Seo et al. used an orthotopic GBM mouse model (intracranial cell implantation) to deliver by CED
NPs formulations loaded with miR-21 inhibitors (170). This treatment prolonged the survival of mice when combined with chemotherapy. Although CED has been used in preclinical and clinical studies, this procedure constitutes a very invasive method of drug delivery. Preclinical and clinical trials using CED to treat GBM and other brain-related conditions have not produced the expected results (171-173).

Another approach to bypass the BBB is intranasal (IN) drug delivery. IN delivery has been used to deliver chitosansiRNA NPs in murine GBM mouse models (174). Sekerdag et al. administered (IN and i.v.) farnesylthiosalicylic acid (FTA) loaded (lipid-cationic) lipid-PEG-PLGA hybrid NPs in the brain of rat glioma (RG2) cell-bearing rats (175) and observed a $55.7 \%$ reduction in tumor area. Although both, i.v. and IN administration routes had a significant anti-cancer effect in vivo, IN delivery might be a better choice of treatment due to its low plasma levels and its non-invasive methods and lower systemic side-effects (175). More studies in GBM mouse models are needed before proposing IN drug administration as a real method to treat brain tumors. Additional procedures to optimize IN RNAi-NP formulations are also required.

A less invasive approach to cross the $\mathrm{BBB}$ is the systemic drug administration (Figure 2). For systemic administration, drugs should be modified to cross the $\mathrm{BBB}$ and reach the tumor cells in the brain. These modifications could allow drugs 
to cross the $\mathrm{BBB}$ using natural transport routes. Transport through BBB includes passive diffusion, paracellular trafficking, facilitated transport, adsorptive endocytosis, and/or receptormediated transcytosis (176). First, a drug that crosses the BBB through passive diffusion (lipid-mediated transport) needs to be small $(<400 \mathrm{Da})$ and it must have high lipid solubility $(<7$ hydrogen bonds with solvent water) (177). For example, TMZ crosses the BBB since it has a molecular weight of $194 \mathrm{Da}$ and it is highly lipophilic. One study revealed that of the $>6,000$ drugs in the Comprehensive Medical Chemistry database, only $6 \%$ are active in the brain (178). Second, small molecules could reach the brain paracellularly, between brain capillary endothelial cells. Under normal physiological conditions, there is no paracellular pathway from blood to the brain (179). This is because adjacent endothelial cells are cemented together through tight junctions, giving the BBB its high resistance property (180). However, in GBM and other neurological disorders, paracellular trafficking of small hydrophilic compounds can occur because the BBB is compromised (163). Also, new imperfect blood vessels are formed in GBM tumors, making the BBB leaky. Hence small NPs can be retained in the tumor tissue by the EPR (181). In addition to structural or architectural vascular abnormalities, impairment of lymphatic drainage and permeability enhancing factors contribute to the EPR effect $(111,182-184)$. In fact, a number of vascular mediators are utilized to augment the EPR effect. One of these mediators is Nitric Oxide (NO), an endogenous mediator that causes vessels to dilate and lower blood pressure, thus promoting EPR (181). A recent study by Yasuda et al. demonstrated that the use of NO-releasing agents has enhanced effects on cancer therapy (185).

Third, therapies can be modified to enable facilitated transport, also known as carrier-mediated transport (CMT), across the BBB. CMT comprises stereospecific pore-based transporters localized in the blood side and the brain side of the brain capillary endothelial cells $(164,165)$. These are dependent on chemical/electrical gradients (mostly dependent on sodium) and require certain structural characteristics for their affinity (186). Some examples of carrier-mediated transporters are glucose, lactate, amino acid, and adenosine transporters (GLUT1, MCT1, LAT1, and CNT2, respectively). Many drugs against brain-related disorders are designed to cross the BBB by using CMT (187). For example, L-DOPA for Parkinson's disease and gabapentin an anti-epileptic drug crosses the BBB through the L-type amino acid transporter 1 (LAT1) (188). Melphalan, an anticancer drug used mainly against multiple myeloma and other cancers, including recurrent brain tumors, crosses the BBB via LAT1 (189). Another anticancer agent that expresses an affinity for the BBB LAT1 transporter is Buthionine Sulfoximine (BSO). BSO is a glutathione synthesis inhibitor that has been used to enhance alkylating drug cytotoxicity and limit development of drug resistance (187). Additional drugs which cross the BBB via CMT should be designed and tested using brain tumor mouse models.

Fourth, effective therapeutic agents could penetrate the brain through adsorptive mediated endocytosis. Adsorptive mediated endocytosis is a vesicle mediated transport system that occurs upon non-specific interactions between positively charged macromolecules and the cell membranes of all cells, including brain capillary endothelial cells (190). Cationic NPs and other drugs conjugated to cell penetrating peptides (CPPs) can enable this type of transport in GBM. CPPs are short peptides derived from a protein-transduction domain that have the ability to enter into most type of cells and promote the delivery of conjugated biomolecules (191). Since most peptideand nucleic acid-based drugs are poorly taken up by cells, the use of conjugated therapeutic agents to CPPs has become a subject of interest in improving drug delivery. Although the mechanisms of internalization of CPPs are not well-understood, recent studies have demonstrated that CPPs does not involve endocytosis nor specific protein transporters, but rather a possible direct transport through the lipid bilayer of membranes (192-194). Studies by Lakkadwala et al. evaluated the influence of inserting a CPP (TAT or QLPVM) in brain targeted with doxorubicin containing liposomes (195). They showed that CPPs significantly improved the systemic delivery of these liposomes across the BBB into glioblastoma tumor cells. Results of this study also demonstrated a higher accumulation of doxorubicin in the mouse brains as compared to free drug without toxicity (195). Although CPP exhibit great delivery potential to send drugs across the BBB, most CPPs are not cell specific, which limits their application in drug delivery.

Fifth, targeting brain capillary endothelial cells could improve drug delivery into brain tumors. Receptor mediated transcytosis (RMT) is one of the most promising mechanisms for systemic delivery for GBM treatment. Here, either small or large molecules can bind to specific receptors on the luminal (blood side) surface of capillary endothelial cells and cross the BBB by transcytosis mechanisms (196). Once macromolecules interact with their target receptor, they are internalized by endocytosis, transported across the cell's cytoplasm, and externalized by exocytosis from the abluminal (brain side) surface of capillary endothelial cells (197). In particular, peptides of apolipoprotein E (ApoE) which bind to low density lipoprotein (LDL) Receptor (198), angiopep-2 which binds to the receptor-related protein 1 (LRP-1) (199), hyaluronan (HA) which binds to CD44 receptor, and transferrin which binds to transferrin receptor have been used (200). For example, Gutkin et al. prepared hyaluronan (HA)-grafted lipid NPs (LNPs) loaded with Polo Like Kinase 1 (PLK1)-targeted siRNA. HA binds to CD44 receptor variant-containing cells (201). Intracranial administration of this formulation in tumor bearing mice (U-87 MG cells implanted intracranially) reduced PLK1 protein levels and prolonged the survival of the mice. Also, the LNPs were accumulated in the tumor tissue when they were systemic administered in C57Bl/6 mice (intracranially implanted with GSCs). Published data from Böckenhoff and collaborators demonstrated that ApoE, in comparison to other BBB permeable therapeutic polypeptides including Angiopep (Ang-2), Apolipoprotein B (ApoB), and Transactivator of Transcription (TAT) exhibited the highest brain accumulation of the lysosomal enzyme Arylsulfatase A (ASA) (202). Studies by Fu et al. demonstrated that incorporating a glucose-RGD derivative into paclitaxel containing liposomes for dual targeting [via GLUT1 (glucose) and integrin $\alpha v \beta 3$ (RGD)] increased liposome accumulation in 
Kunming mice bearing C6 glioma tumors compared to paclitaxel alone (203).

Saw et al. developed aptamer-like peptide (aptide)-decorated liposomal nanoplatform for siRNA delivery into GBM cells. The NPs were decorated with PEG and with a surface-encoded aptide to precisely target the extra-domain $\mathrm{B}$ (EDB) of fibronectin, a glycoprotein overexpressed on glioma cells. They used siRNA to target cyclophilin A (СурA), a gene upregulated in brain cancer cells that plays a critical role in malignant transformation and maintenance of glioma cell stemness (204). This aptamer NP formulation decreased cell growth in vitro, and when administed IV. reduced tumor growth in a s.c. GBM mouse model. Recently, Zou et al. used an angiopep-2-decorated nanocapsule with PLK1-targeted siRNA inside (205). Systemic administration of this NPs formulation in an orthotopic GBM mouse model (intracranial implantation of U-87MG cells) increased their circulation in plasma and their accumulation in the GBM cells (205).

Another modification to improve systemic treatments against CNS disorders is the conjugation of drugs with peptide sequences from neurotropic viruses-capable of invading and infecting neural tissue. Some viruses, like the West Nile virus, are able to get through the BBB by infecting immune cells that enter the CNS (206), while others like the ZIKA virus have shown to directly infect the BBB endothelial and glial cells (207). However, most viruses enter the CNS through the peripheral nervous system (PNS), using the nerve tracts to transit from the periphery to the CNS, evading the BBB (208). The rabies virus is an example of a neurotropic virus that uses axonal transport (209). This virus contains a rabies virus glycoprotein (RVG) which is the part of the virus responsible for neural interaction and which has been used for drug delivery to the brain (210). Evidence indicates that RVG interacts specifically with the nicotinic acetylcholine receptor (nACnR) in neural cells (211-214). Early studies by Kumur et al. showed that RVG peptide significantly increased oligonucleotide delivery (siRNA) to brain $(p=0.001)$ in comparison to other organs (liver and spleen), making it an excellent candidate to improve RNA delivery to brain tumors (212). In a recent study, our research team compared the accumulation levels of RVG- and ApoEdecorated liposomal nanoparticles (with AuNPs-OMI inside liposomes) in orthotopic GBM mouse models (106). We showed that ApoE decorated NPs accumulate to a higher degree in GBM cells compared with RVG-decorated NPs (106). In a separate study, Kong et al. prepared arginine-glycine-aspartic (RGD) functionalized dendrimer-entrapped AuNPs (Au DENPs) and polyethylene glycol (PEG) spacers attached to siRNA molecules against vascular endothelial growth factor (VEGF) and B-cell lymphoma/leukemia-2 (Bcl-2). Effective silencing of both, VEGF and $\mathrm{Bcl}-2$ was observed in both in vitro and in vivo studies $(215,216)$. Similar results were obtained when dendrimers were replaced by polyethyleneimine (PEI) (217).

Molecular Trojan horse (MTH) is an engineered endogenous peptide monoclonal antibody (MAb) that can undergo receptor mediated transport across BBB (218). Several species-specific Mab MTHs have been developed for brain drug delivery (219). In humans, a genetically engineered form of human insulin receptor (HIR) Mab have been produced to enable drug delivery into the brain. RNAi-based molecules can be attached to MTH by avidin-biotin conjugation (219). This attachment has no effect on the hybridization of the RNAi molecule with its RNA target (219). A combination of MTH and liposomes, called Trojan Hourse Liposomes (THL), have been used for siRNA delivery. Zhang et al. implanted U-87 MG cells in the brain of nude mice and 5 days later injected (i.v.) a EGFR-targeted short hairpin RNA loaded PEGylatedliposomes. Liposomes were derivatized with two monoclonal antibodies, a murine MAb to the human insulin receptor and a rat MAb to the mouse transferrin receptor. Weekly administration of this THL increased mouse survival by $88 \%$ while EGFR expression was significantly reduced. Other THL formulations for drug delivery into the brain are being developed (220).

\section{CONCLUSIONS AND FUTURE REMARKS}

Currently, an arsenal of technologies for GBM diagnosis are available in the clinical setting. Also, the classification of CNS tumors according to pathological and molecular parameters is an advantage as more precise GBM diagnostic and prognostic tools are now possible. Although many therapies for GBM treatment are in the clinic and in clinical trials, GBM is still an incurable and deadly disease. Deregulation of several miRNAs and lncRNAs have been reported in GBM cell lines and GBM tumor samples and they represent promising targets against GBM. Given the nature of miRNA binding to multiple mRNAs, the precise molecular and biological consequences of targeting a miRNA should be carefully studied. These studies should be conducted not only in the tumor cells but also in tumor microenvironment. Regarding the IncRNAs, more studies are needed to fully understand the role of these regulatory and signaling molecules in health and disease. Targeting some miRNAs and lncRNAs with RNAi molecules in GBM cell lines and GBM mouse models have resulted in beneficial effects. However, the delivery of RNAi molecules to the brain is a challenge as $\mathrm{BBB}$ precluded the passage of most substances into the brain.

Biodegradable NPs are ideal carriers to delivery RNAi molecules to GBM tumors. IN and i.v. delivery are the least invasive routes to deliver RNAi-NPs (and other drugs) to the brain. Although thousands of NPs have been suggested for the delivery of RNAi molecules for GBM treatment, few have been tested in animal models. Some reports have shown that IV delivery of RNAi-NPs cross the BBB (by RMT) and efficiently accumulate in the tumor cells of orthotopic GBM mouse models. More studies implanting patient derived GBM tumors and/or GBM cell lines in the mouse brain (intracranial, orthotropic) are required. Also, to model a genuine treatment, the therapy should be administrated IV or IN. Although, the use of SC GBM mouse models to test the therapeutic benefits of a novel RNAi-based therapies is a first approach, this does not represent a real GBM model, mainly because the tumor microenvironment and the presence of $\mathrm{BBB}$ are 
not considered. Designing NPs able to discriminate tumor $v s$. normal cell is another critical challenge to overcomes. Therefore, multidisciplinary research teams should work together in order to design rational NPs able to cross the BBB. In this way the RNAi-based therapies for GBM treatment will become a clinical reality.

\section{AUTHOR CONTRIBUTIONS}

PEV-M, RKS, and CC wrote sections of the manuscript. RKS elaborated the figure of the manuscript. PEV-M made corrections to the final version of the manuscript. All authors contributed to manuscript revision, read, and approved the submitted version.

\section{REFERENCES}

1. Urbańska K, Sokołowska J, Szmidt M, Sysa P. Glioblastoma multiforme-an overview. Contemp Oncol. (2014) 18:307. doi: 10.5114/wo.2014.40559

2. De Vleeschouwer S. Glioblastoma. Brisbane, AU: Codon Publications. (2017). doi: 10.15586/codon.glioblastoma.2017

3. Vredenburgh JJ, Desjardins A, Herndon JE, Dowell JM, Reardon DA, Quinn JA, et al. Phase II trial of bevacizumab and irinotecan in recurrent malignant glioma. Clin Cancer Res. (2007) 13:12539. doi: 10.1158/1078-0432.CCR-06-2309

4. Alcedo-Guardia R, Labat E, Blas-Boria D, Vivas-Mejia P. Diagnosis and new treatment modalities for glioblastoma: do they improve patient survival? Curr Mol Med. (2016) 16:447-64. doi: 10.2174/1566524016666160429120150

5. Reid JM, Stevens DC, Rubin J, Ames MM. Pharmacokinetics of 3methyl-(triazen-1-yl) imidazole-4-carboximide following administration of temozolomide to patients with advanced cancer. Clin Cancer Res. (1997) 3:2393-8.

6. Minniti G, De Sanctis V, Muni R, Rasio D, Lanzetta G, Bozzao A, et al. Hypofractionated radiotherapy followed by adjuvant chemotherapy with temozolomide in elderly patients with glioblastoma. J Neurooncol. (2009) 91:95-100. doi: 10.1007/s11060-008-9689-z

7. Stupp R, Mason WP, Van Den Bent MJ, Weller M, Fisher B, Taphoorn MJ, et al. Radiotherapy plus concomitant and adjuvant temozolomide for glioblastoma. New Engl J Med. (2005) 352:987-96. doi: 10.1056/NEJMoa043330

8. Anjum K, Shagufta BI, Abbas SQ, Patel S, Khan I, Shah S, et al. Current status and future therapeutic perspectives of glioblastoma multiforme (GBM) therapy: A review. Biomed Pharmacother. (2017) 92:6819. doi: 10.1016/j.biopha.2017.05.125

9. Nagpal S. The role of BCNU polymer wafers (Gliadel) in the treatment of malignant glioma. Neurosurg Clin. (2012) 23:289-95. doi: 10.1016/j.nec.2012.01.004

10. Esteller M, Garcia-Foncillas J, Andion E, Goodman SN, Hidalgo OF, Vanaclocha V, et al. Inactivation of the DNA-repair gene MGMT and the clinical response of gliomas to alkylating agents. N Engl J Med. (2000) 343:1350-4. doi: 10.1056/NEJM200011093431901

11. Tan AC, Ashley DM, López GY, Malinzak M, Friedman HS, Khasraw M. Management of glioblastoma: State of the art and future directions. CA Cancer J Clin. (2020) 70:299-312. doi: 10.3322/caac.21613

12. Mende AL, Schulte JD, Okada H, Clarke JL. Current advances in immunotherapy for glioblastoma. Curr Oncol Rep. (2021) 23:1-18. doi: 10.1007/s11912-020-01007-5

13. Meacham CE, Morrison SJ. Tumour heterogeneity and cancer cell plasticity. Nature. (2013) 501:328-37. doi: 10.1038/nature12624

14. Zhang, Y., Cruickshanks, N., Pahuski, M., Yuan, F., Dutta, A., Schiff, D., et al. (2017). Noncoding RNAs in Glioblastoma. S. De Vleeschouwer, editor. Leuven: Exon Publications. doi: 10.15586/codon.glioblastoma.2017.ch6

\section{FUNDING}

This work was supported in part by the National Institute on Minority Health and Health Disparities (NIMHD) CCRHD (U54MD007600) and institutional seed funds from the UPR Comprehensive Cancer Center.

\section{ACKNOWLEDGMENTS}

The authors would like to thank Dr. Arthur D. Tinoco (Department of Chemistry, University of Puerto Rico- Río Piedras) for providing the facility of BioRender software for figures creation. We would like to thanks Mary K. Bruno, Ph.D. for the scientific editing and critical revision of the manuscript.

15. Friedman RC, Farh KKH, Burge CB, Bartel DP. Most mammalian mRNAs are conserved targets of microRNAs. Genome Res. (2009) 19:92105. doi: 10.1101/gr.082701.108

16. Zhang $\mathrm{P}, \mathrm{Wu} \mathrm{W}$, Chen Q, Chen $\mathrm{M}$. Non-coding RNAs and their integrated networks. J Integr Bioinform. (2019) 16:27. doi: 10.1515/jib-2019-0027

17. Lozada-Delgado EL, Grafals-Ruiz N, Vivas-Mejía PE. RNA interference for glioblastoma therapy: Innovation ladder from the bench to clinical trials. Life Sci. (2017) 188:26-36. doi: 10.1016/j.lfs.2017.08.027

18. Lee RC, Feinbaum RL, Ambros V. The C. elegans heterochronic gene lin-4 encodes small RNAs with antisense complementarity to lin-14. Cell. (1993) 75:843-54. doi: 10.1016/0092-8674(93)90529-Y

19. Visone R, Croce CM. MiRNAs and cancer. Am J Pathol. (2009) 174:11318. doi: 10.2353/ajpath.2009.080794

20. Rupaimoole R, Calin GA, Lopez-Berestein G, Sood AK. miRNA deregulation in cancer cells and the tumor microenvironment. Cancer Discov. (2016) 6:235-46. doi: 10.1158/2159-8290.CD-15-0893

21. Brannan CI, Dees EC, Ingram RS, Tilghman SM. The product of the H19 gene may function as an RNA. Mol Cell Biol. (1990) 10:2836. doi: 10.1128/MCB.10.1.28

22. Brown CJ, Ballabio A, Rupert JL, Lafreniere RG, Grompe M, Tonlorenzi $\mathrm{R}$, et al. A gene from the region of the human $\mathrm{X}$ inactivation centre is expressed exclusively from the inactive X chromosome. Nature. (1991) 349:38-44. doi: 10.1038/349038a0

23. Shimoni Y, Friedlander G, Hetzroni G, Niv G, Altuvia S, Biham O, et al. Regulation of gene expression by small non-coding RNAs: a quantitative view. Mol Syst Biol. (2007) 3:138. doi: 10.1038/msb4100181

24. Sun W, Yang Y, Xu C, Guo J. Regulatory mechanisms of long noncoding RNAs on gene expression in cancers. Cancer Genet. (2017) 216:10510. doi: 10.1016/j.cancergen.2017.06.003

25. Pang KC, Frith MC, Mattick JS. Rapid evolution of noncoding RNAs: lack of conservation does not mean lack of function. Trends Genet. (2006) 22:1-5. doi: 10.1016/j.tig.2005.10.003

26. Ransohoff JD, Wei Y, Khavari PA. The functions and unique features of long intergenic non-coding RNA. Nat Rev Mol Cell Biol. (2018) 19:143. doi: $10.1038 / \mathrm{nrm} .2017 .104$

27. Hezroni H, Koppstein D, Schwartz MG, Avrutin A, Bartel DP, Ulitsky I. Principles of long noncoding RNA evolution derived from direct comparison of transcriptomes in 17 species. Cell Rep. (2015) 11:111022. doi: 10.1016/j.celrep.2015.04.023

28. Mccreight JC, Schneider SE, Wilburn DB, Swanson WJ. Evolution of microRNA in primates. PLoS ONE. (2017) 12:e0176596. doi: 10.1371/journal.pone.0176596

29. Sana J, Faltejskova P, Svoboda M, Slaby O. Novel classes of non-coding RNAs and cancer. J Transl Med. (2012) 10:103. doi: 10.1186/1479-5876-10-103

30. Guennewig B, Cooper AA. The central role of noncoding RNA in the brain. Int Rev Neurobiol. (2014) 116:153-94. doi: 10.1016/B978-0-12-801105-8.00007-2 
31. Nie JH, Li TX, Zhang XQ, Liu J. Roles of non-coding RNAs in normal human brain development, brain tumor, and neuropsychiatric disorders. Non-Coding RNA. (2019) 5:36. doi: 10.3390/ncrna5020036

32. Sun M, Kraus WL. From discovery to function: the expanding roles of long noncoding RNAs in physiology and disease. Endocr Rev. (2015) 36:2564. doi: 10.1210/er.2014-1034

33. Zhu H, Wu H, Liu X, Li B, Chen Y, Ren X, et al. Regulation of autophagy by a beclin 1-targeted microRNA, miR-30a, in cancer cells. Autophagy. (2009) 5:816-23. doi: 10.4161/auto.9064

34. Gregory RI, Yan KP, Amuthan G, Chendrimada T, Doratotaj B, Cooch N, et al. The microprocessor complex mediates the genesis of microRNAs. Nature. (2004) 432:235-40. doi: 10.1038/nature03120

35. Ciafre S, Galardi S, Mangiola A, Ferracin M, Liu CG, Sabatino $\mathrm{G}$, et al. Extensive modulation of a set of microRNAs in primary glioblastoma. Biochem Biophys Res Commun. (2005) 334:1351-8. doi: 10.1016/j.bbrc.2005.07.030

36. Brower JV, Clark PA, Lyon W, Kuo JS. MicroRNAs in cancer: Glioblastoma and glioblastoma cancer stem cells. Neurochem Int. (2014) 77:6877. doi: 10.1016/j.neuint.2014.06.002

37. Mizoguchi M, Guan Y, Yoshimoto K, Hata N, Amano T, Nakamizo A, et al. Clinical implications of microRNAs in human glioblastoma. Front Oncol. (2013) 3:19. doi: 10.3389/fonc.2013.00019

38. Ahir BK, Ozer H, Engelhard HH, Lakka SS. MicroRNAs in glioblastoma pathogenesis and therapy: A comprehensive review. Crit Rev Oncol. (2017) 120:22-33. doi: 10.1016/j.critrevonc.2017.10.003

39. Banelli B, Forlani A, Allemanni G, Morabito A, Pistillo MP, Romani M. (2017). MicroRNA in glioblastoma: an overview. Int J Genomics. (2017). doi: 10.1155/2017/7639084

40. Corsten MF, Miranda R, Kasmieh R, Krichevsky AM, Weissleder R, Shah K. MicroRNA-21 knockdown disrupts glioma growth in vivo and displays synergistic cytotoxicity with neural precursor cell-delivered S-TRAIL in human gliomas. Cancer Res. (2007) 67:8994-9000. doi: 10.1158/0008-5472.CAN-07-1045

41. Belter A, Rolle K, Piwecka M, Fedoruk-Wyszomirska A, NaskretBarciszewska MZ, Barciszewski J. Inhibition of miR-21 in glioma cells using catalytic nucleic acids. Sci Rep. (2016) 6:1-13. doi: 10.1038/srep24516

42. Piwecka $M$, Rolle $K$, Belter A, Barciszewska AM, Zywicki M, Michalak $M$, et al. Comprehensive analysis of microRNA expression profile in malignant glioma tissues. Mol Oncol. (2015) 9:1324-40. doi: 10.1016/j.molonc.2015.03.007

43. Srinivasan S, Patric IRP, Somasundaram K. A ten-microRNA expression signature predicts survival in glioblastoma. PLoS ONE. (2011) 6:e17438. doi: 10.1371/journal.pone.0017438

44. Jin D, Lee $H$. Prioritizing cancer-related microRNAs by integrating microRNA and mRNA datasets. Sci Rep. (2016) 6:35350. doi: 10.1038/srep35350

45. Chen H, Lu Q, Fei X, Shen L, Jiang D, Dai D. miR-22 inhibits the proliferation, motility, and invasion of human glioblastoma cells by directly targeting SIRT1. Tumor Biol. (2016) 37:6761-8. doi: 10.1007/s13277-015-4575-8

46. Lin Z, Fang D. The roles of SIRT1 in cancer. Genes Cancer. (2013) 4:97104. doi: 10.1177/1947601912475079

47. Boissinot M, King H, Adams M, Higgins J, Shaw G, Ward T, et al. Profiling cytotoxic microRNAs in pediatric and adult glioblastoma cells by highcontent screening, identification, and validation of miR-1300. Oncogene. (2020) 39:5292-306. doi: 10.1038/s41388-020-1360-y

48. Yang Y, Dodbele S, Park T, Glass R, Bhat K, Sulman EP, et al. MicroRNA-29a inhibits glioblastoma stem cells and tumor growth by regulating the PDGF pathway. J Neurooncol. (2019) 145:23-34. doi: 10.1007/s11060-019-03275-Z

49. Lu M, Wang Y, Zhou S, Xu J, Li J, Tao R, et al. MicroRNA-370 suppresses the progression and proliferation of human astrocytoma and glioblastoma by negatively regulating $\beta$-catenin and causing activation of FOXO3a. Exp Ther Med. (2018) 15:1093-8. doi: 10.3892/etm.2017.5494

50. Rossi M, Magnoni L, Miracco C, Mori E, Tosi P, Pirtoli L, et al. $\beta$-catenin and Gli1 are prognostic markers in glioblastoma. Cancer Biol Ther. (2011) 11:753-61. doi: 10.4161/cbt.11.8.14894

51. Li T, Ma J, Han X, Jia Y, Yuan H, Shui S, et al. MicroRNA-320 enhances radiosensitivity of glioma through down-regulation of sirtuin type 1 by directly targeting forkhead box protein M1. Transl Oncol. (2018) 11:20512. doi: 10.1016/j.tranon.2017.12.008

52. Shenouda SK, Alahari SK. MicroRNA function in cancer: oncogene or a tumor suppressor? Cancer Metastasis Rev. (2009) 28:369-78. doi: 10.1007/s10555-009-9188-5

53. Zhou P, Xu W, Peng X, Luo Z, Xing Q, Chen X, et al. Largescale screens of miRNA-mRNA interactions unveiled that the $3^{\prime}$ UTR of a gene is targeted by multiple miRNAs. PLoS ONE. (2013) 8:e68204. doi: 10.1371/journal.pone.0068204

54. Teplyuk NM, Uhlmann EJ, Gabriely G, Volfovsky N, Wang Y, Teng J, et al. Therapeutic potential of targeting micro RNA-10b in established intracranial glioblastoma: first steps toward the clinic. EMBO Mol Med. (2016) 8:26887. doi: $10.15252 / \mathrm{emmm} .201505495$

55. Lopez-Bertoni H, Kotchetkov IS, Mihelson N, Lal B, Rui Y, Ames $\mathrm{H}$, et al. A Sox2: miR-486-5p axis regulates survival of GBM cells by inhibiting tumor suppressor networks. Cancer Res. (2020) 80:164455. doi: 10.1158/0008-5472.CAN-19-1624

56. Zhou X, Ren Y, Moore L, Mei M, You Y, Xu P, et al. Downregulation of miR-21 inhibits EGFR pathway and suppresses the growth of human glioblastoma cells independent of PTEN status. Lab Investig. (2010) 90:14455. doi: 10.1038/labinvest.2009.126

57. Ofek P, Calderón M, Mehrabadi FS, Krivitsky A, Ferber S, Tiram $\mathrm{G}$, et al. Restoring the oncosuppressor activity of microRNA-34a in glioblastoma using a polyglycerol-based polyplex. Nanomedicine. (2016) 12:2201-14. doi: 10.1016/j.nano.2016.05.016

58. Zhao C, Guo R, Guan F, Ma S, Li M, Wu J, et al. MicroRNA-128-3p Enhances the chemosensitivity of temozolomide in glioblastoma by targeting c-Met and EMT. Sci Rep. (2020) 10:1-12. doi: 10.1038/s41598-020-65331-3

59. Lozada-Delgado EL, Grafals-Ruiz N, Miranda-Román MA, SantanaRivera Y, Valiyeva F, Rivera-Díaz M, et al. Targeting MicroRNA-143 leads to inhibition of glioblastoma tumor progression. Cancers. (2018) 10:382. doi: $10.3390 /$ cancers 10100382

60. Chillón I, Marcia M. The molecular structure of long non-coding RNAs: Emerging patterns and functional implications. Crit Rev Biochem Mol Biol. (2020) 55:662-90. doi: 10.1080/10409238.2020.1828259

61. Qin T, Li J, Zhang KQ. Structure, regulation, and function of linear and circular long non-coding RNAs. Front Genet. (2020) 11:150. doi: 10.3389/fgene.2020.00150

62. Stackhouse CT, Gillespie GY, Willey CD. Exploring the roles of lncRNAs in GBM pathophysiology and their therapeutic potential. Cells. (2020) 9:2369. doi: $10.3390 /$ cells9112369

63. Ma L, Cao J, Liu L, Du Q, Li Z, Zou D, et al. LncBook: a curated knowledgebase of human long non-coding RNAs. Nucleic Acids Res. (2019) 47:D128-34. doi: 10.1093/nar/gkz073

64. Li Y, Syed J, Sugiyama H. RNA-DNA triplex formation by long noncoding RNAs. Cell Chem Biol. (2016) 23:132533. doi: 10.1016/j.chembiol.2016.09.011

65. Yao RW, Wang Y, Chen LL. Cellular functions of long noncoding RNAs. Nat Cell Biol. (2019) 21:542-51. doi: 10.1038/s41556-019-0311-8

66. Subhash S, Andersson PO, Kosalai ST, Kanduri C, Kanduri M. Global DNA methylation profiling reveals new insights into epigenetically deregulated protein coding and long noncoding RNAs in CLL. Clin Epigenetics. (2016) 8:1-15. doi: 10.1186/s13148-016-0274-6

67. Zhang X, Kiang KM, Zhang GP, Leung GK. Long non-coding RNAs dysregulation and function in glioblastoma stem cells. Non-Coding RNA. (2015) 1:69-86. doi: 10.3390/ncrna1010069

68. Cai J, Zhang J, Wu P, Yang W, Ye Q, Chen Q, et al. Blocking LINC00152 suppresses glioblastoma malignancy by impairing mesenchymal phenotype through the miR-612/AKT2/NF-kB pathway. J Neurooncol. (2018) 140:22536. doi: 10.1007/s11060-018-2951-0

69. Reon BJ, Karia BTR, Kiran M, Dutta A. LINC00152 promotes invasion through a $3^{\prime}$-hairpin structure and associates with prognosis in glioblastoma. Mol Cancer Res. (2018) 16:1470-82. doi: 10.1158/1541-7786.MCR-18-0322

70. Liang Q, Guan G, Li X, Wei C, Wu J, Cheng P, et al. Profiling pro-neural to mesenchymal transition identifies a lncRNA signature in glioma. J Transl Med. (2020) 18:1-16. doi: 10.1186/s12967-020-02552-0

71. Li C, Zheng H, Hou W, Bao H, Xiong J, Che W, et al. Long non-coding RNA linc00645 promotes TGF- $\beta$-induced epithelial-mesenchymal transition 
by regulating miR-205-3p-ZEB1 axis in glioma. Cell Death Dis. (2019) 10:1-17. doi: 10.1038/s41419-019-1948-8

72. Ren J, Yang Y, Xue J, Xi Z, Hu L, Pan SJ, et al. Long noncoding RNA SNHG7 promotes the progression and growth of glioblastoma via inhibition of miR-5095. Biochem Biophys Res Commun. (2018) 496:7128. doi: 10.1016/j.bbrc.2018.01.109

73. Chen Y, Yuan S, Ning T, Xu H, Guan B. SNHG7 Facilitates glioblastoma progression by functioning as a molecular sponge for MicroRNA-449b-5p and thereby increasing MYCN expression. Technol Cancer Res Treat. (2020) 19:1533033820945802. doi: 10.1177/1533033820945802

74. Han M, Wang S, Fritah S, Wang X, Zhou W, Yang N, et al. Interfering with long non-coding RNA MIR22HG processing inhibits glioblastoma progression through suppression of Wnt/B-catenin signalling. Brain. (2020) 143:512-30. doi: 10.1093/brain/awz406

75. Chen Z, Li S, Shen L, Wei X, Zhu H, Wang X, et al. NF-kappa B interacting long noncoding RNA enhances the Warburg effect and angiogenesis and is associated with decreased survival of patients with gliomas. Cell Death Dis. (2020) 11:1-18. doi: 10.1038/s41419-020-2520-2

76. Yuan HD, Quan HY, Zhang Y, Kim SH, Chung SH. 20 (S)Ginsenoside Rg3-induced apoptosis in HT-29 colon cancer cells is associated with AMPK signaling pathway. Mol Med Rep. (2010) 3:825-31. doi: $10.3892 / \mathrm{mmr} .2010 .328$

77. Cai T, Liu Y, Xiao J. Long noncoding RNA MALAT 1 knockdown reverses chemoresistance to temozolomide via promoting micro RNA-101 in glioblastoma. Cancer Med. (2018) 7:1404-15. doi: 10.1002/cam4.1384

78. Wu P, Cai J, Chen Q, Han B, Meng X, Li Y, et al. Lnc-TALC promotes O 6methylguanine-DNA methyltransferase expression via regulating the c-Met pathway by competitively binding with miR-20b-3p. Nat Commun. (2019) 10:1-15. doi: 10.1038/s41467-019-10025-2

79. Liu B, Zhou J, Wang C, Chi Y, Wei Q, Fu Z, et al. LncRNA SOX2OT promotes temozolomide resistance by elevating SOX2 expression via ALKBH5mediated epigenetic regulation in glioblastoma. Cell Death Dis. (2020) 11:118. doi: 10.1038/s41419-020-2540-y

80. Ramaiah MJ, Divyapriya K, Kumar SK, Rajesh Y. Drug-induced modifications and modulations of microRNAs and long non-coding RNAs for future therapy against Glioblastoma Multiforme. Gene. (2020) 723:144126. doi: 10.1016/j.gene.2019.144126

81. Li N, Kang Y, Wang L, Huff S, Tang R, Hui H, et al. ALKBH5 regulates antiPD-1 therapy response by modulating lactate and suppressive immune cell accumulation in tumor microenvironment. Proc Nat Acad Sci USA. (2020) 117:20159-70. doi: 10.1073/pnas.1918986117

82. Mazor G, Levin L, Picard D, Ahmadov U, Carén H, Borkhardt A, et al. The lncRNA TP73-AS1 is linked to aggressiveness in glioblastoma and promotes temozolomide resistance in glioblastoma cancer stem cells. Cell Death Dis. (2019) 10:1-14. doi: 10.1038/s41419-019-1477-5

83. Liu X, Yue C, Shi L, Liu G, Cao Q, Shan Q, et al. MALT1 is a potential therapeutic target in glioblastoma and plays a crucial role in EGFR-induced NF-KB activation. J Cell Mol Med. (2020) 24:755062. doi: $10.1111 / \mathrm{jcmm} .15383$

84. Gooding M, Browne LP, Quinteiro FM, Selwood DL. siRNA delivery: from lipids to cell-penetrating peptides and their mimics. Chem Biol Drug Des. (2012) 80:787-809. doi: 10.1111/cbdd.12052

85. Parveen S, Sahoo SK. Polymeric nanoparticles for cancer therapy. J Drug Target. (2008) 16:108-23. doi: 10.1080/10611860701794353

86. Zhou J, Shum KT, Burnett JC, Rossi JJ. Nanoparticle-based delivery of RNAi therapeutics: progress and challenges. Pharmaceuticals. (2013) 6:85107. doi: $10.3390 /$ ph6010085

87. Guerrero-Cázares H, Tzeng SY, Young NP, Abutaleb AO, QuiñonesHinojosa A, Green JJ. Biodegradable polymeric nanoparticles show high efficacy and specificity at DNA delivery to human glioblastoma in vitro and in vivo. ACS Nano. (2014) 8:5141-53. doi: 10.1021/nn501197v

88. Krishnamurthy S, Vaiyapuri R, Zhang L, Chan JM. Lipid-coated polymeric nanoparticles for cancer drug delivery. Biomater Sci. (2015) 3:92336. doi: 10.1039/C4BM00427B

89. Lopez-Bertoni H, Kozielski KL, Rui Y, Lal B, Vaughan H, Wilson DR, et al. Bioreducible polymeric nanoparticles containing multiplexed cancer stem cell regulating miRNAs inhibit glioblastoma growth and prolong survival. Nano Lett. (2018) 18:4086-94. doi: 10.1021/acs.nanolett.8b00390
90. Wang R, Degirmenci V, Xin H, Li Y, Wang L, Chen J, et al. PEICoated $\mathrm{Fe} 3 \mathrm{O} 4$ nanoparticles enable efficient delivery of therapeutic siRNA targeting REST into glioblastoma cells. Int J Mol Sci. (2018) 19:2230. doi: $10.3390 / \mathrm{ijms} 19082230$

91. Dong Y, Love KT, Dorkin JR, Sirirungruang S, Zhang Y, Chen D, et al. Lipopeptide nanoparticles for potent and selective siRNA delivery in rodents and nonhuman primates. Proc Nat Acad Sci USA. (2014) 111:395560. doi: 10.1073/pnas.1322937111

92. Yang ZZ, Li JQ, Wang ZZ, Dong DW, Qi XR. Tumor-targeting dual peptidesmodified cationic liposomes for delivery of siRNA and docetaxel to gliomas. Biomaterials. (2014) 35:5226-39. doi: 10.1016/j.biomaterials.2014.03.017

93. Hans ML, Lowman AM. Biodegradable nanoparticles for drug delivery and targeting. Curr Opin Solid State Mater Sci. (2002) 6:319-27. doi: 10.1016/S1359-0286(02)00117-1

94. Yu D, Khan OF, Suvà ML, Dong B, Panek WK, Xiao T, et al. Multiplexed RNAi therapy against brain tumor-initiating cells via lipopolymeric nanoparticle infusion delays glioblastoma progression. Proc Nat Acad Sci USA. (2017) 114:E6147-56. doi: 10.1073/pnas.1701911114

95. Anselmo AC, Mitragotri S. Nanoparticles in the clinic: An update. Bioeng Translat Med. (2019) 4:e10143. doi: 10.1002/btm2.10143

96. Kozielski KL, Ruiz-Valls A, Tzeng SY, Guerrero-Cázares H, Rui Y, Li Y, et al. Cancer-selective nanoparticles for combinatorial siRNA delivery to primary human GBM in vitro and in vivo. Biomaterials. (2019) 209:7987. doi: 10.1016/j.biomaterials.2019.04.020

97. Liu Y, Zou Y, Feng C, Lee A, Yin J, Chung R, et al. Charge conversional biomimetic nanocomplexes as a multifunctional platform for boosting orthotopic glioblastoma RNAi therapy. Nano Lett. (2020) 20:163746. doi: 10.1021/acs.nanolett.9b04683

98. Betzer O, Shilo M, Opochinsky R, Barnoy E, Motiei M, Okun E, et al. The effect of nanoparticle size on the ability to cross the blood-brain barrier: an in vivo study. Nanomedicine. (2017) 12:1533-46. doi: 10.2217/nnm-2017-0022

99. Fröhlich E. The role of surface charge in cellular uptake and cytotoxicity of medical nanoparticles. Int J Nanomed. (2012) 7:5577. doi: $10.2147 /$ IJN.S36111

100. He C, Hu Y, Yin L, Tang C, Yin C. Effects of particle size and surface charge on cellular uptake and biodistribution of polymeric nanoparticles. Biomaterials. (2010) 31:3657-66. doi: 10.1016/j.biomaterials.2010.01.065

101. Walkey CD, Olsen JB, Guo H, Emili A, Chan WC. Nanoparticle size and surface chemistry determine serum protein adsorption and macrophage uptake. J Am Chem Soc. (2012) 134:2139-47. doi: 10.1021/ja 2084338

102. Qiu J, Kong L, Cao X, Li A, Wei P, Wang L, et al. Enhanced delivery of therapeutic siRNA into glioblastoma cells using dendrimer-entrapped gold nanoparticles conjugated with $\beta$-cyclodextrin. Nanomaterials. (2018) 8:131. doi: 10.3390/nano8030131

103. Li L, Liu Y, Yang J, Zhang Q, Lu M, Wang X, et al. Targeted Combination therapy for glioblastoma by co-delivery of doxorubicin, YAPsiRNA and gold nanorods. YAP-siRNA Gold Nanorods. (2021) 63:81-90. doi: 10.2139/ssrn. 3417473

104. Mishra DK, Shandilya R, Mishra PK. Lipid based nanocarriers: a translational perspective. Nanomedicine. (2018) 14:202350. doi: 10.1016/j.nano.2018.05.021

105. Díaz MR, Vivas-Mejia PE. Nanoparticles as drug delivery systems in cancer medicine: emphasis on RNAi-containing nanoliposomes. Pharmaceuticals. (2013) 6:1361-80. doi: 10.3390/ph6111361

106. Grafals-Ruiz N, Rios-Vicil CI, Lozada-Delgado EL, Quiñones-Díaz BI, Noriega-Rivera RA, Martínez-Zayas G, et al. Brain targeted gold liposomes improve RNAi delivery for glioblastoma. Int J Nanomed. (2020) 15:2809. doi: 10.2147/IJN.S241055

107. Saw PE, Park J, Lee E, Ahn S, Lee J, Kim H, et al. Effect of PEG pairing on the efficiency of cancer-targeting liposomes. Theranostics. (2015) 5:746. doi: 10.7150/thno.10732

108. Yin H, Kanasty RL, Eltoukhy AA, Vegas AJ, Dorkin JR, Anderson DG. Non-viral vectors for gene-based therapy. Nat Rev Genet. (2014) 15:54155. doi: $10.1038 / \mathrm{nrg} 3763$

109. Mohamed M, Abu Lila AS, Shimizu T, Alaaeldin E, Hussein A, Sarhan HA, et al. PEGylated liposomes: immunological responses. Sci Technol Adv Mater. (2019) 20:710-24. doi: 10.1080/14686996.2019.1627174 
110. Hatakeyama H, Akita H, Harashima H. The polyethyleneglycol dilemma: advantage and disadvantage of PEGylation of liposomes for systemic genes and nucleic acids delivery to tumors. Biolo Pharm Bull. (2013) 36:8929. doi: 10.1248/bpb.b13-00059

111. Nel A, Ruoslahti E, Meng H. New Insights Into Permeability as in the Enhanced Permeability and Retention Effect of Cancer Nanotherapeutics. ACS Nano. (2017) 11:9567-9. doi: 10.1021/acsnano.7b07214

112. Ravi V, Madhankumar AB, Abraham T, Slagle-Webb B, Connor JR. Liposomal delivery of ferritin heavy chain 1 (FTH1) siRNA in patient xenograft derived glioblastoma initiating cells suggests different sensitivities to radiation and distinct survival mechanisms. PLoS ONE. (2019) 14:e0221952. doi: 10.1371/journal.pone.0221952

113. Kato T, Natsume A, Toda H, Iwamizu H, Sugita T, Hachisu R, et al. Efficient delivery of liposome-mediated MGMT-siRNA reinforces the cytotoxity of temozolomide in GBM-initiating cells. Gene Ther. (2010) 17:136371. doi: $10.1038 /$ gt.2010.88

114. Danhier F, Messaoudi K, Lemaire L, Benoit JP, Lagarce F. Combined anti-Galectin-1 and anti-EGFR siRNA-loaded chitosan-lipid nanocapsules decrease temozolomide resistance in glioblastoma: in vivo evaluation. Int J Pharm. (2015) 481:154-61. doi: 10.1016/j.ijpharm.2015.01.051

115. Van Woensel M, Wauthoz N, Rosière R, Mathieu V, Kiss R, Lefranc F, et al. Development of siRNA-loaded chitosan nanoparticles targeting Galectin-1 for the treatment of glioblastoma multiforme via intranasal administration. $J$ Control Release. (2016) 227:71-81. doi: 10.1016/j.jconrel.2016.02.032

116. Van Woensel M, Mathivet T, Wauthoz N, Rosière R, Garg AD, Agostinis $\mathrm{P}$, et al. Sensitization of glioblastoma tumor micro-environment to chemoand immunotherapy by Galectin-1 intranasal knock-down strategy. Sci Rep. (2017) 7:1-14. doi: 10.1038/s41598-017-01279-1

117. Ye C, Pan B, Xu H, Zhao Z, Shen J, Lu J, et al. Co-delivery of GOLPH3 siRNA and gefitinib by cationic lipid-PLGA nanoparticles improves EGFR-targeted therapy for glioma. J Mol Med. (2019) 97:157588. doi: 10.1007/s00109-019-01843-4

118. Li F, Danquah M, Mahato RI. Synthesis and characterization of amphiphilic lipopolymers for micellar drug delivery. Biomacromolecules. (2010) 11:261020. doi: $10.1021 / \mathrm{bm} 100561 \mathrm{v}$

119. Dahlman JE, Barnes C, Khan OF, Thiriot A, Jhunjunwala S, Shaw $\mathrm{TE}$, et al. In vivo endothelial siRNA delivery using polymeric nanoparticles with low molecular weight. Nat Nanotechnol. (2014) 9:648. doi: 10.1038/nnano.2014.84

120. Singh SK, Hawkins C, Clarke ID, Squire JA, Bayani J, Hide T, et al. Identification of human brain tumour initiating cells. Nature. (2004) 432:396-401. doi: 10.1038/nature03128

121. Green JJ, Zugates GT, Langer R, Anderson DG. Poly ( $\beta$-amino esters): procedures for synthesis and gene delivery. In: M. Belting, editor. Macromolecular Drug Delivery. Berlin: Springer. (2009). p. 53-63. doi: 10.1007/978-1-59745-429-2_4

122. Lopez-Bertoni H, Lal B, Li A, Caplan M, Guerrero-Cazares H, Eberhart CG, et al. DNMT-dependent suppression of microRNA regulates the induction of GBM tumor-propagating phenotype by Oct4 and Sox2. Oncogene. (2015) 34:3994-4004. doi: 10.1038/onc.2014.334

123. Lopez-Bertoni H, Lal B, Michelson N, Guerrero-Cazares H, QuinonesHinojosa A, Li Y, et al. Epigenetic modulation of a miR-296-5p: HMGA1 axis regulates Sox 2 expression and glioblastoma stem cells. Oncogene. (2016) 35:4903-13. doi: 10.1038/onc.2016.22

124. Zhao S, Karp JM, Joshi N. Toxin-Mediated siRNA Delivery. Trends Pharmacol Sci. (2020) 41:511-3. doi: 10.1016/j.tips.2020.06.006

125. Auger A, Park M, Nitschke F, Minassian LM, Beilhartz GL, Minassian BA, et al. Efficient delivery of structurally diverse protein cargo into mammalian cells by a bacterial toxin. Mol Pharm. (2015) 12:296271. doi: 10.1021/acs.molpharmaceut.5b00233

126. Dyer PD, Shepherd TR, Gollings AS, Shorter SA, Gorringe-Pattrick MA, Tang CK, et al. Disarmed anthrax toxin delivers antisense oligonucleotides and siRNA with high efficiency and low toxicity. J Control Rel. (2015) 220:316-28. doi: 10.1016/j.jconrel,0.201510054

127. Arnold AE, Smith LJ, Beilhartz G, Bahlmann LC, Jameson E, Melnyk R, et al. Attenuated diphtheria toxin mediates siRNA delivery. Sci Adv. (2020) 6:eaaz4848. doi: 10.1126/sciadv.aaz4848
128. Vader P, Mol EA, Pasterkamp G, Schiffelers RM. Extracellular vesicles for drug delivery. Adv Drug Deliv Rev. (2016) 106:14856. doi: 10.1016/j.addr.2016.02.006

129. Pullan JE, Confeld MI, Osborn JK, Kim J, Sarkar K, Mallik S. Exosomes as drug carriers for cancer therapy. Mol Pharm. (2019) 16:178998. doi: 10.1021/acs.molpharmaceut.9b00104

130. Jayaseelan VP. Emerging role of exosomes as promising diagnostic tool for cancer. Cancer Gene Ther. (2020) 27:395-8. doi: 10.1038/s41417-019-0136-4

131. Saeedi S, Israel S, Nagy C, Turecki G. The emerging role of exosomes in mental disorders. Transl Psychiatry. (2019) 9:1-11. doi: 10.1038/s41398-019-0459-9

132. Katakowski M, Buller B, Zheng X, Lu Y, Rogers T, Osobamiro O, et al. Exosomes from marrow stromal cells expressing miR-146b inhibit glioma growth. Cancer Lett. (2013) 335:201-4. doi: 10.1016/j.canlet.2013.02.019

133. Fareh M, Almairac F, Turchi L, Burel-Vandenbos F, Paquis P, Fontaine D, et al. Cell-based therapy using miR-302-367 expressing cells represses glioblastoma growth. Cell Death Dis. (2017) 8:e2713. doi: 10.1038/cddis.2017.117

134. Fareh M, Turchi L, Virolle V, Debruyne D, Almairac F, Divonne SDLF, et al. The miR 302-367 cluster drastically affects self-renewal and infiltration properties of glioma-initiating cells through CXCR4 repression and consequent disruption of the SHH-GLI-NANOG network. Cell Death Differentiation. (2012) 19:232-44. doi: 10.1038/cdd.2011.89

135. Lee HK, Finniss S, Cazacu S, Bucris E, Ziv-Av A, Xiang C, et al. Mesenchymal stem cells deliver synthetic microRNA mimics to glioma cells and glioma stem cells and inhibit their cell migration and self-renewal. Oncotarget. (2013) 4:346. doi: 10.18632/oncotarget.868

136. Wang B, Wu ZH, Lou PY, Chai C, Han SY, Ning JF, et al. Human bone marrow-derived mesenchymal stem cell-secreted exosomes overexpressing microRNA-34a ameliorate glioblastoma development via down-regulating MYCN. Cell Oncol. (2019) 42:783-99. doi: 10.1007/s13402-019-00461-Z

137. Yu L, Gui S, Liu Y, Qiu X, Zhang G, Zhang XA, et al. Exosomes derived from microRNA-199a-overexpressing mesenchymal stem cells inhibit glioma progression by down-regulating AGAP2. Aging (Albany NY). (2019) 11:5300. doi: 10.18632/aging.102092

138. Watanabe R. Takase-Yoden S. Gene expression of neurotropic retrovirus in the CNS. Prog. Brain Res. (1995). 105:25562. doi: 10.1016/S0079-6123(08)63302-6

139. Peltékian E, Garcia L, Danos O. Neurotropism and retrograde axonal transport of a canine adenoviral vector: a tool for targeting key structures undergoing neurodegenerative processes. Mol Therapy. (2002) 5:2532. doi: $10.1006 / \mathrm{mthe} .2001 .0517$

140. Braun E, Zimmerman T, Hur TB, Reinhartz E, Fellig Y, Panet A, et al. Neurotropism of herpes simplex virus type 1 in brain organ cultures. J Gene Virol. (2006) 87:2827-37. doi: 10.1099/vir.0.81850-0

141. Viel T, Monfared P, Schelhaas S, Fricke IB, Kuhlmann MT, Fraefel C, et al. Optimizing glioblastoma temozolomide chemotherapy employing lentiviral-based anti-MGMT shRNA technology. Mol Therapy. (2013) 21:570-9. doi: 10.1038/mt.2012.278

142. Yang Y, Zhang Z, Wang R, Ma W, Wei J, Li G. siRNA-mediated knockdown of SMC1A expression suppresses the proliferation of glioblastoma cells. $\mathrm{Mol}$ Cell Biochem. (2013) 381:209-15. doi: 10.1007/s11010-013-1704-9

143. Matsuda M, Yamamoto T, Matsumura A, Kaneda Y. Highly efficient eradication of intracranial glioblastoma using Eg5 siRNA combined with HVJ envelope. Gene Ther. (2009) 16:1465-76. doi: 10.1038/gt.2009.99

144. Saydam O, Glauser DL, Heid I, Turkeri G, Hilbe M, Jacobs AH, et al. Herpes simplex virus 1 amplicon vector-mediated siRNA targeting epidermal growth factor receptor inhibits growth of human glioma cells in vivo. Mol Therapy. (2005) 12:803-12. doi: 10.1016/j.ymthe.2005.07.534

145. Saydam O, Saydam N, Glauser D, Pruschy M, Dinh-Van V, Hilbe M, et al. HSV-1 amplicon-mediated post-transcriptional inhibition of Rad51 sensitizes human glioma cells to ionizing radiation. Gene Ther. (2007) 14:1143-51. doi: 10.1038/sj.gt.3302967

146. Li L, Yang L, Scudiero D, Miller S, Yu Z, Stukenberg P, et al. Development of recombinant adeno-associated virus vectors carrying small interfering RNA (shHec1)-mediated depletion of kinetochore $\mathrm{Hecl}$ protein in tumor cells. Gene Ther. (2007) 14:814-27. doi: 10.1038/sj.gt.3302933 
147. Lee TJ, Haque F, Shu D, Yoo JY, Li H, Yokel RA, et al. RNA nanoparticle as a vector for targeted siRNA delivery into glioblastoma mouse model. Oncotarget. (2015) 6:14766. doi: 10.18632/oncotarget.3632

148. Lee TJ, Yoo JY, Shu D, Li H, Zhang J, Yu JG, et al. RNA nanoparticle-based targeted therapy for glioblastoma through inhibition of oncogenic miR-21. Mol Therapy. (2017) 25:1544-55. doi: 10.1016/j.ymthe.2016.11.016

149. Maguire CA, Balaj L, Sivaraman S, Crommentuijn MH, Ericsson M, Mincheva-Nilsson L, et al. Microvesicle-associated AAV vector as a novel gene delivery system. Mol Therapy. (2012) 20:960-71. doi: 10.1038/mt.2011.303

150. Hudry E, Martin C, Gandhi S, György B, Scheffer DI, Mu D, et al. Exosomeassociated AAV vector as a robust and convenient neuroscience tool. Gene Ther. (2016) 23:380-92. doi: 10.1038/gt.2016.11

151. Mozhei OG, Teschemacher A, Kasparov S. Viral vectors as gene therapy agents for treatment of glioblastoma. Cancers. (2020) 12:3724. doi: $10.3390 /$ cancers 12123724

152. Caffery B, Lee JS, Alexander-Bryant AA. Vectors for glioblastoma gene therapy: viral \& non-viral delivery strategies. Nanomaterials. (2019) 9:105. doi: 10.3390/nano9010105

153. Liu P, Wang Y, Wang Y, Kong Z, Chen W, Li J, et al. Effects of oncolytic viruses and viral vectors on immunity in glioblastoma. Gene Ther. (2020) 15:1-12. doi: 10.1038/s41434-020-00207-9

154. Khan N, Maurya S, Bammidi S, Jayandharan GR. AAV6 vexosomes mediate robust suicide gene delivery in a murine model of hepatocellular carcinoma. Mol Therapy-Methods Clin Dev. (2020) 17:497-504. doi: 10.1016/j.omtm.2020.03.006

155. Daneman R, Prat A. The blood-brain barrier. Cold Spring Harb Perspect Biol. (2015) 7:a020412. doi: 10.1101/cshperspect.a020412

156. Katsi V, Marketou M, Maragkoudakis S, Didagelos M, Charalambous G, Parthenakis F, et al. Blood-brain barrier dysfunction: the undervalued frontier of hypertension. J Hum Hypertens. (2020) 34:682-91. doi: 10.1038/s41371-020-0352-2

157. Ben-Zvi A, Lacoste B, Kur E, Andreone BJ, Mayshar Y, Yan H, et al. Mfsd2a is critical for the formation and function of the blood-brain barrier. Nature. (2014) 509:507-11. doi: 10.1038/nature13324

158. Armulik A, Genové G, Mäe M, Nisancioglu MH, Wallgard E, Niaudet C, et al. Pericytes regulate the blood-brain barrier. Nature. (2010) 468:55761. doi: 10.1038/nature09522

159. Elali A, Thériault $\mathrm{P}$, Rivest $\mathrm{S}$. The role of pericytes in neurovascular unit remodeling in brain disorders. Int J Mol Sci. (2014) 15:645374. doi: 10.3390/ijms15046453

160. Giaume C, Koulakoff A, Roux L, Holcman D, Rouach N. Astroglial networks: a step further in neuroglial and gliovascular interactions. Nat Rev Neurosci. (2010) 11:87-99. doi: 10.1038/nrn2757

161. Alvarez JI, Katayama T, Prat A. Glial influence on the blood brain barrier. Glia. (2013) 61:1939-58. doi: 10.1002/glia.22575

162. Horng S, Therattil A, Moyon S, Gordon A, Kim K, Argaw AT, et al. Astrocytic tight junctions control inflammatory CNS lesion pathogenesis. J Clin Invest. (2017) 127:3136-51. doi: 10.1172/JCI91301

163. Arvanitis CD, Ferraro GB, Jain RK. The blood-brain barrier and bloodtumour barrier in brain tumours and metastases. Nat Rev Cancer. (2020) 20:26-41. doi: 10.1038/s41568-019-0205-x

164. Pardridge WM. The blood-brain barrier: bottleneck in brain drug development. NeuroRx. (2005) 2:3-14. doi: 10.1602/neurorx.2.1.3

165. Pardridge WM. Molecular biology of the blood-brain barrier. Mol Biotechnol. (2005) 30:57-69. doi: 10.1385/MB:30:1:057

166. Konofagou E, Tunga YS, Choia J, Deffieuxa T, Baseria B, Vlachosa F. Ultrasound-induced blood-brain barrier opening. Curr Pharm Biotechnol. (2012) 13:1332-45. doi: 10.2174/138920112800624364

167. Bunevicius A, Mcdannold NJ, Golby AJ. Focused ultrasound strategies for brain tumor therapy. Operat Neurosurg. (2020) 19:9-18. doi: 10.1093/ons/opz374

168. Sun P, Liu DZ, Jickling GC, Sharp FR, Yin KJ. MicroRNA-based therapeutics in central nervous system injuries. J Cereb Blood Flow Metabo. (2018) 38:1125-48. doi: 10.1177/0271678X18773871

169. Kim DG, Kim KH, Seo YJ, Yang H, Marcusson EG, Son E, et al. Anti-miR delivery strategies to bypass the blood-brain barrier in glioblastoma therapy. Oncotarget. (2016) 7:29400. doi: 10.18632/oncotarget.8837
170. Seo YE, Suh HW, Bahal R, Josowitz A, Zhang J, Song E, et al. Nanoparticle-mediated intratumoral inhibition of miR21 for improved survival in glioblastoma. Biomaterials. (2019) 201:87-98. doi: 10.1016/j.biomaterials.2019.02.016

171. Sampson JH, Archer G, Pedain C, Wembacher-Schröder E, Westphal M, Kunwar S, et al. Poor drug distribution as a possible explanation for the results of the PRECISE trial. J Neurosurg. (2010) 113:3019. doi: 10.3171/2009.11.JNS091052

172. Shi M, Sanche L. (2019). Convection-enhanced delivery in malignant gliomas: a review of toxicity and efficacy. J Oncol. (2019) 2019:9342796. doi: 10.1155/2019/9342796

173. Stine CA, Munson JM. Convection-enhanced delivery: connection to and impact of interstitial fluid flow. Front Oncol. (2019) 9:966. doi: 10.3389/fonc.2019.00966

174. Malhotra M, Tomaro-Duchesneau C, Saha S, Prakash S. Intranasal delivery of chitosan-siRNA nanoparticle formulation to the brain. In: K. K. Jain, editor. Drug Delivery System. Berlin: Springer (2014). p. 23347. doi: 10.1007/978-1-4939-0363-4_15

175. Sekerdag E, Lüle S, Pehlivan SB, Öztürk N, Kara A, Kaffashi A, et al. A potential non-invasive glioblastoma treatment: Nose-to-brain delivery of farnesylthiosalicylic acid incorporated hybrid nanoparticles. J Control Rel. (2017) 261:187-98. doi: 10.1016/j.jconrel.2017.06.032

176. Pulgar VM. Transcytosis to cross the blood brain barrier, new advancements and challenges. Front Neurosci. (2019) 12:1019. doi: 10.3389/fnins.2018.01019

177. Pardridge WM. Drug transport across the blood-brain barrier. J Cerebr Blood Flow Metab. (2012) 32:1959-72. doi: 10.1038/jcbfm.2012.126

178. Ghose AK, Viswanadhan VN, Wendoloski JJ. A knowledge-based approach in designing combinatorial or medicinal chemistry libraries for drug discovery. $1 \mathrm{~A}$ qualitative and quantitative characterization of known drug databases. J Combinat Chem. (1999) 1:55-68. doi: 10.1021/cc9800071

179. Grant GA, Abbott NJ, Janigro D. Understanding the physiology of the blood-brain barrier: in vitro models. Physiology. (1998) 13:28793. doi: 10.1152/physiologyonline.1998.13.6.287

180. Stamatovic SM, Keep RF, Andjelkovic AV. Brain endothelial cell-cell junctions: how to "open" the blood brain barrier. Curr Neuropharmacol. (2008) 6:179-92. doi: 10.2174/157015908785777210

181. Maeda H, Tsukigawa K, Fang J. A retrospective 30 years after discovery of the enhanced permeability and retention effect of solid tumors: next-generation chemotherapeutics and photodynamic therapy-problems, solutions, and prospects. Microcirculation. (2016) 23:173-82. doi: 10.1111/micc.12228

182. Bae YH, Park K. Targeted drug delivery to tumors: myths, reality and possibility. J Control Rel. (2011) 153:198. doi: 10.1016/j.jconrel.2011.06.001

183. Fang J, Nakamura $H$, Maeda $H$. The EPR effect: unique features of tumor blood vessels for drug delivery, factors involved, and limitations and augmentation of the effect. Adv Drug Deliv Rev. (2011) 63:13651. doi: 10.1016/j.addr.2010.04.009

184. Prabhakar U, Maeda H, Jain RK, Sevick-Muraca EM, Zamboni W, Farokhzad OC, et al. Challenges and key considerations of the enhanced permeability and retention effect for nanomedicine drug delivery in oncology. Cancer Res. (2013) 73:2412-7. doi: 10.1158/0008-5472.CAN-12-4561

185. Yasuda H, Yanagihara K, Nakayama K, Mio T, Sasaki T, Asada $M$, et al. Therapeutic applications of nitric oxide for malignant tumor in animal models and human studies. In: B. Bonavida, editor. Nitric Oxide (NO) and Cancer. Berlin: Springer (2010). p. 419-441. doi: 10.1007/978-1-4419-1432-3_22

186. Barar J, Rafi MA, Pourseif MM, Omidi Y. Blood-brain barrier transport machineries and targeted therapy of brain diseases. BioImpacts: BI. (2016) 6:225. doi: 10.15171/bi.2016.30

187. Smith QR. Carrier-mediated transport to enhance drug delivery to brain. In: Int Congr Ser. (2005) 1277:63-74. doi: 10.1016/j.ics.2005.02.012

188. Puris E, Gynther M, Auriola S, Huttunen KM. L-Type amino acid transporter 1 as a target for drug delivery. Pharm Res. (2020) 37:117. doi: 10.1007/s11095-020-02826-8

189. Goldenberg GJ, Lam H, Begleiter A. Active carrier-mediated transport of melphalan by two separate amino acid transport systems in LPC-1 plasmacytoma cells in vitro. J Biol Chem. (1979) 254:1057-64. doi: 10.1016/S0021-9258(17)34167-4 
190. Hervé F, Ghinea N, Scherrmann JM. CNS delivery via adsorptive transcytosis. AAPS J. (2008) 10:455-72. doi: 10.1208/s12248-008-9055-2

191. Lindgren M, Hällbrink M, Prochiantz A, Langel Ü. Cellpenetrating peptides. Trends Pharmacol Sci. (2000) 21:99103. doi: 10.1016/S0165-6147(00)01447-4

192. Derossi D, Joliot AH, Chassaing G, Prochiantz A. The third helix of the Antennapedia homeodomain translocates through biological membranes. J Biol Chem. (1994) 269:10444-50. doi: 10.1016/S0021-9258(17)34080-2

193. Vives E, Brodin P, Lebleu B. A truncated HIV-1 Tat protein basic domain rapidly translocates through the plasma membrane and accumulates in the cell nucleus. J Biol Chem. (1997) 272:16010-7. doi: 10.1074/jbc.272.25.16010

194. Richard JP, Melikov K, Vives E, Ramos C, Verbeure B, Gait MJ, et al. Cellpenetrating peptides: a reevaluation of the mechanism of cellular uptake. $J$ Biol Chem. (2003) 278:585-90. doi: 10.1074/jbc.M209548200

195. Lakkadwala S, Dos Santos Rodrigues B, Sun C, Singh J. Biodistribution of TAT or QLPVM coupled to receptor targeted liposomes for delivery of anticancer therapeutics to brain in vitro and in vivo. Nanomedicine. (2020) 23:102112. doi: 10.1016/j.nano.2019.102112

196. Jones AR, Shusta EV. Blood-brain barrier transport of therapeutics via receptor-mediation. Pharm Res. (2007) 24:175971. doi: 10.1007/s11095-007-9379-0

197. Brown VI, Greene MI. Molecular and cellular mechanisms of receptor-mediated endocytosis. DNA Cell Biol. (1991) 10:399-409. doi: 10.1089/dna.1991.10.399

198. Liao F, Yoon H, Kim J. Apolipoprotein E metabolism and functions in brain and its role in Alzheimer's disease. Curr Opin Lipidol. (2017) 28:60. doi: 10.1097/MOL.0000000000000383

199. Spuch C, Ortolano S, Navarro C. LRP-1 and LRP-2 receptors function in the membrane neuron. Trafficking mechanisms and proteolytic processing in Alzheimer's disease. Front Physiol. (2012) 3:269. doi: 10.3389/fphys.2012.00269

200. Misra S, Hascall VC, Markwald RR, Ghatak S. Interactions between hyaluronan and its receptors (CD44, RHAMM) regulate the activities of inflammation and cancer. Front Immunol. (2015) 6:201. doi: 10.3389/fimmu.2015.00201

201. Gutkin A, Peer D, Cohen Z. DDIS-03 harnessing siRNA nanomedicine for therapeutic gene silencing in glioblastoma. Neuro-oncology. (2017) 19:vi59. doi: 10.1093/neuonc/nox168.239

202. Böckenhoff A, Cramer S, Wölte P, Knieling S, Wohlenberg C, Gieselmann $\mathrm{V}$, et al. Comparison of five peptide vectors for improved brain delivery of the lysosomal enzyme arylsulfatase A. J Neurosci. (2014) 34:31229. doi: 10.1523/JNEUROSCI.4785-13.2014

203. Fu Q, Zhao Y, Yang Z, Yue Q, Xiao W, Chen Y, et al. Liposomes actively recognizing the glucose transporter GLUT1 and integrin avß3 for dual-targeting of glioma. Archiv der Pharmazie. (2019) 352:1800219. doi: 10.1002/ardp.201800219

204. Saw PE, Zhang A, Nie Y, Zhang L, Xu Y, Xu X. Tumor-associated Fibronectin targeted liposomal Nanoplatform for Cyclophilin a siRNA delivery and targeted malignant Glioblastoma therapy. Front Pharmacol. (2018) 9:1194. doi: 10.3389/fphar.2018.01194

205. Zou Y, Sun X, Wang Y, Yan C, Liu Y, Li J, et al. Single siRNA nanocapsules for effective siRNA brain delivery and glioblastoma treatment. Adv Mater. (2020) 32:2000416. doi: 10.1002/adma.202000416

206. Roe K, Kumar M, Lum S, Orillo B, Nerurkar VR, Verma S. West Nile virus-induced disruption of the blood-brain barrier in mice is characterized by the degradation of the junctional complex proteins and increase in multiple matrix metalloproteinases. J Gen Virol. (2012) 93:1193. doi: 10.1099/vir.0.040899-0

207. Alimonti JB, Ribecco-Lutkiewicz M, Sodja C, Jezierski A, Stanimirovic $\mathrm{DB}$, Liu $\mathrm{Q}$, et al. Zika virus crosses an in vitro human blood brain barrier model. Fluids Barriers CNS. (2018) 15:1-9. doi: 10.1186/s12987-018$0100-\mathrm{y}$
208. Spindler KR, Hsu TH. Viral disruption of the blood-brain barrier. Trends Microbiol. (2012) 20:282-90. doi: 10.1016/j.tim.2012.03.009

209. Mazarakis ND, Azzouz M, Rohll JB, Ellard FM, Wilkes FJ, Olsen AL, et al. Rabies virus glycoprotein pseudotyping of lentiviral vectors enables retrograde axonal transport and access to the nervous system after peripheral delivery. Hum Mol Genet. (2001) 10:2109-21. doi: 10.1093/hmg/10.19.2109

210. Huey R, Hawthorne S, Mccarron P. The potential use of rabies virus glycoprotein-derived peptides to facilitate drug delivery into the central nervous system: a mini review. J Drug Target. (2017) 25:37985. doi: 10.1080/1061186X.2016.1223676

211. Lafon M. Rabies virus receptors. J Neurovirol. (2005) 11:827. doi: $10.1080 / 13550280590900427$

212. Kumar P, Wu H, Mcbride JL, Jung KE, Kim MH, Davidson BL, et al. Transvascular delivery of small interfering RNA to the central nervous system. Nature. (2007) 448:39-43. doi: 10.1038/nature05901

213. Liu Y, Huang R, Han L, Ke W, Shao K, Ye L, et al. Brain-targeting gene delivery and cellular internalization mechanisms for modified rabies virus glycoprotein RVG29 nanoparticles. Biomaterials. (2009) 30:4195202. doi: 10.1016/j.biomaterials.2009.02.051

214. Fu A, Zhao Z, Gao F, Zhang M. Cellular uptake mechanism and therapeutic utility of a novel peptide in targeted-delivery of proteins into neuronal cells. Pharm Res. (2013) 30:2108-17. doi: 10.1007/s11095-013-1068-6

215. Kong L, Alves CS, Hou W, Qiu J, MöHwald H, Tomá S, et al. RGD peptidemodified dendrimer-entrapped gold nanoparticles enable highly efficient and specific gene delivery to stem cells. ACS Appl Mater Interfaces. (2015) 7:4833-43. doi: 10.1021/am508760w

216. Kong $\mathrm{L}, \mathrm{Wu} \mathrm{Y}$, Alves CS, Shi X. Efficient delivery of therapeutic siRNA into glioblastoma cells using multifunctional dendrimerentrapped gold nanoparticles. Nanomedicine. (2016) 12:310315. doi: 10.2217/nnm-2016-0240

217. Kong L, Qiu J, Sun W, Yang J, Shen M, Wang L, et al. Multifunctional PEI-entrapped gold nanoparticles enable efficient delivery of therapeutic siRNA into glioblastoma cells. Biomater Sci. (2017) 5:258-66. doi: 10.1039/C6BM00708B

218. Pardridge WM. Blood-brain barrier delivery of protein and non-viral gene therapeutics with molecular Trojan horses. J Control Rel. (2007) 122:3458. doi: 10.1016/j.jconrel.2007.04.001

219. Pardridge WM. shRNA and siRNA delivery to the brain. Adv Drug Deliv Rev. (2007) 59:141-52. doi: 10.1016/j.addr.2007.03.008

220. Zhang Y, Zhang YF, Bryant J, Charles A, Boado RJ, Pardridge WM. Intravenous RNA interference gene therapy targeting the human epidermal growth factor receptor prolongs survival in intracranial brain cancer. Clin Cancer Res. (2004) 10:3667-77. doi: 10.1158/1078-0432.CCR-03-0740

Conflict of Interest: The authors declare that the research was conducted in the absence of any commercial or financial relationships that could be construed as a potential conflict of interest.

Publisher's Note: All claims expressed in this article are solely those of the authors and do not necessarily represent those of their affiliated organizations, or those of the publisher, the editors and the reviewers. Any product that may be evaluated in this article, or claim that may be made by its manufacturer, is not guaranteed or endorsed by the publisher.

Copyright $(\odot) 2021$ Sharma, Calderon and Vivas-Mejia. This is an open-access article distributed under the terms of the Creative Commons Attribution License (CC BY). The use, distribution or reproduction in other forums is permitted, provided the original author(s) and the copyright owner(s) are credited and that the original publication in this journal is cited, in accordance with accepted academic practice. No use, distribution or reproduction is permitted which does not comply with these terms. 